Article

\title{
Lipophilicity, Pharmacokinetic Properties, and Molecular Docking Study on SARS-CoV-2 Target for Betulin Triazole Derivatives with Attached 1,4-Quinone
}

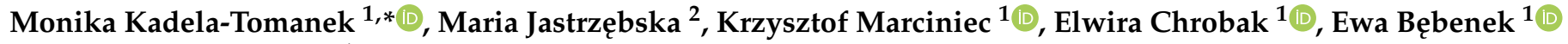 \\ and Stanisław Boryczka 1 \\ 1 Department of Organic Chemistry, Faculty of Pharmaceutical Sciences in Sosnowiec, Medical University of \\ Silesia, Katowice, 4 Jagiellońska Str., 41-200 Sosnowiec, Poland; kmarciniec@sum.edu.pl (K.M.); \\ echrobak@sum.edu.pl (E.C.); ebebenek@sum.edu.pl (E.B.); boryczka@sum.edu.pl (S.B.) \\ 2 Silesian Center for Education and Interdisciplinary Research, Institute of Physics, University of Silesia, \\ 75 Pułku Piechoty 1a, 41-500 Chorzów, Poland; maria.jastrzebska@us.edu.pl \\ * Correspondence: mkadela@sum.edu.pl; Tel.: +48-32-3641666
}

Citation: Kadela-Tomanek, M.; Jastrzębska, M.; Marciniec, K.; Chrobak, E.; Bębenek, E.; Boryczka, S. Lipophilicity, Pharmacokinetic Properties, and Molecular Docking Study on SARS-CoV-2 Target for Betulin Triazole Derivatives with Attached 1,4-Quinone. Pharmaceutics 2021, 13, 781. https://doi.org/ 10.3390/pharmaceutics13060781

Academic Editor:

Sourav Bhattacharjee

Received: 6 May 2021

Accepted: 20 May 2021

Published: 23 May 2021

Publisher's Note: MDPI stays neutral with regard to jurisdictional claims in published maps and institutional affiliations.

Copyright: (c) 2021 by the authors. Licensee MDPI, Basel, Switzerland. This article is an open access article distributed under the terms and conditions of the Creative Commons Attribution (CC BY) license (https:/ / creativecommons.org/licenses/by/ $4.0 /)$.

\begin{abstract}
A key parameter in the design of new active compounds is lipophilicity, which influences the solubility and permeability through membranes. Lipophilicity affects the pharmacodynamic and toxicological profiles of compounds. These parameters can be determined experimentally or by using different calculation methods. The aim of the research was to determine the lipophilicity of betulin triazole derivatives with attached 1,4-quinone using thin layer chromatography in a reverse phase system and a computer program to calculate its theoretical model. The physiochemical and pharmacokinetic properties were also determined by computer programs. For all obtained parameters, the similarity analysis and multilinear regression were determined. The analyses showed that there is a relationship between structure and properties under study. The molecular docking study showed that betulin triazole derivatives with attached 1,4-quinone could inhibit selected SARS-CoV-2 proteins. The MLR regression showed that there is a correlation between affinity scoring values $(\Delta G)$ and the physicochemical properties of the tested compounds.
\end{abstract}

Keywords: 1,4-quinone; betulin; lipophilicity; molecular docking; SARS-CoV-2 proteins

\section{Introduction}

Nowadays, the search for new drugs requires the application of computational chemistry, including experimental and in silico analysis of physicochemical properties, pharmacokinetic features, ADMET analysis, and quantitative structure-activity relationship (QSAR) research [1,2]. The therapeutic potential of a drug depends on its distribution in the body. Often, substances with high biological activity show low bioavailability and high toxicity to healthy tissues. Nanocarriers, including liposomes, micelles, and polymer nanoparticles, enable the improvement of the biodistribution of substances. Incorporation of the hydrophobic core into hydrophilic nanotransporters can effectively influence the solubility of the drug, which contributes to the improvement of permeability through cell membranes $[3,4]$.

A key parameter in the design of new active compounds is lipophilicity, which influences the solubility and permeability through membranes. Lipophilicity affects the pharmacodynamic and toxicological profiles of compounds. These parameters can be determined experimentally or by using different calculation methods. Experimental lipophilicity is usually determined by chromatographic methods, such as reversed phase thin layer chromatography (RP-TLC), normal phase thin layer chromatography (NP-TLC), or reversed phase high performance liquid chromatography (RP-HPLC). Theoretical methods are the second way to determine lipophilicity. However, the calculated value of lipophilicity 
depends on the algorithm employed for calculation, and for many compounds it differs from the experimental ones [5-7].

Natural substances, especially secondary metabolites, are often an inspiration to obtain semisynthetic compounds, which exhibit high biological activity. Microorganisms produce many secondary metabolites that affect antibacterial, antiviral, and anticancer activities. The Streptomyces species produce compounds containing the 5,8-quinolinedione moiety, such as streptonigrin, lavendamycin, and streptonigron, which exhibit a wide spectrum of biological activity (Figure 1) [8,9]. Previous studies dealt with the modification of 5,8quinolinedione moiety at the C-2, C-6, and C-7 positions and they showed that such modification can lead to changes in biological activity [10-19].
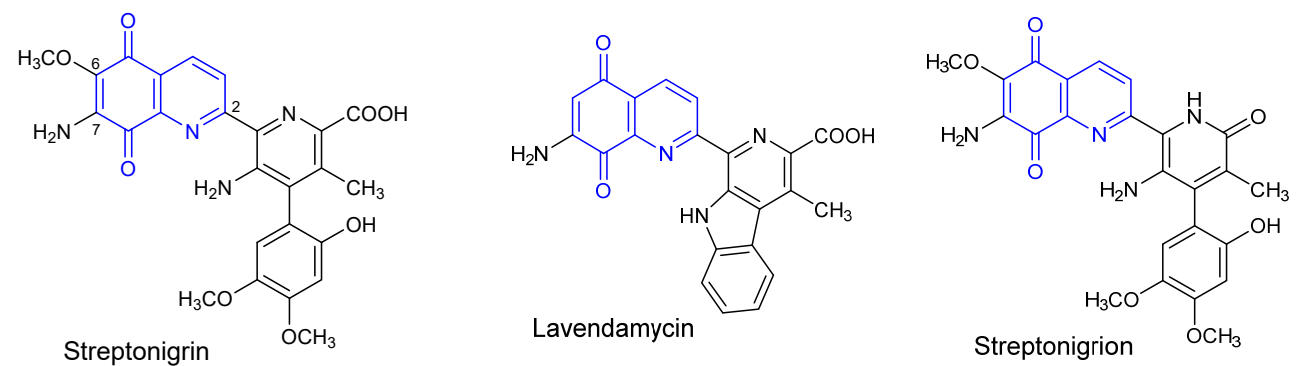

Figure 1. Chemical structure of 7-amino-5,8-quinolinedione antibiotics.

Studies on the lipophilicity of 5,8-quinolinedione derivatives were carried out applying the RP-TLC and RP-HPLC methods. It was found that there is a relationship between lipophilicity and in silico pharmacokinetic properties of synthetic 5,8-quinolinedione derivatives [20-23]. As a continuation of our previous research, we determined the lipophilicity experimentally as well as by using computational methods for the betulin triazole derivatives with attached 1,4-quinone. The physicochemical and pharmacokinetic properties influence the bioavailability and biological activity of compounds when they are determined by computer programs. The correlation between lipophilicity and in silico determined structural parameters have been analyzed in this study.

The tested compounds contain two active moieties, i.e., 1,4-quinone and betulin. The main mechanism of activity for 1,4-quinone derivatives is the interaction with NQO1 protein, for which the overexpression is observed in many types of cancer cell lines $[8,10,24]$. The betulin derivatives show a wide spectrum of activities including anticancer, antiviral, antibacterial, and anti-inflammatory effects. The use of betulin and its derivatives in treatment is limited due to low bioavailability and low water solubility. For these reasons, the use of new drug nanoencapsulation procedures and/or nanoparticle-based delivery methods are a key issue. These are issues of nanomedicine interest [25,26].

Over the past decade, many betulin derivatives exhibiting high antiviral activity against human immunodeficiency virus (HIV-1), herpes simplex (HSV-1), enteric cytopathogenic human orphan virus (ECHO-6), and human cytomegalovirus (HCMV) were described [27-31]. The high antiviral activity of betulin derivatives has aroused interest as a possibility of using them in the treatment of COVID-19 [32-35]. The aim of the present study was to characterize the triazole betulin derivatives with attached 1,4-quinone in terms of their lipophilicity, pharmacokinetic properties, and molecular docking with SARSCoV-2 proteins, such as Mpro and PLpro. Moreover, we examined the correlation between scoring values $(\Delta G)$ and structural properties.

\section{Materials and Methods}

\subsection{Data Set}

In this study, a series of triazole betulin derivatives with attached 1,4-quinone (1-16), as well as triazole betulin derivatives (17-20), were used. According to literature data [36], the reaction between triazole betulin derivatives (17-20) and 1,4-quinone compounds in the 
presence of potassium carbonate in tetrahydrofuran lead to the hybrids 1-16. The chemical structures of compounds 1-20 are presented in Table 1.

Table 1. Chemical structure and biological activity of compounds 1-20.

\begin{tabular}{|c|c|c|c|}
\hline Compound & Chemical Structure & Compound & Chemical Structure \\
\hline 1 & & 2 & \\
\hline 3 & & 4 & \\
\hline 5 & & 6 & \\
\hline 7 & & 8 & \\
\hline 9 & & 10 & \\
\hline 11 & & 12 & \\
\hline 13 & & 14 & \\
\hline
\end{tabular}


Table 1. Cont.

Compound Chemical Structure Compound

\subsection{Experimental Lipophilicity}

The experimental lipophilicity was determined using the RP-TLC method according to the literature $[20,21,37]$. We used the modified silica gel as a stationary phase and (tris-hydroxymethyl)aminomethane $(0.2 \mathrm{M}, \mathrm{pH}=7.4)$ with acetone as a mobile phase. The percent of organic solvent volume was varied within the range of $60-90 \%$ in $5 \%$ increments.

The compounds 1-20 were dissolved in chloroform $(1.0 \mathrm{mg} / \mathrm{mL})$, then $5 \mu \mathrm{L}$ of sample solution was applied to the chromatographic plates with a micropipette. Spots were visualized by spraying with $10 \%$ ethanol solution of sulfuric acid (VI) and then heated up to $110^{\circ} \mathrm{C}$.

The obtained values of retardation factor $\left(R_{f}\right)$ were converted to $R_{M}$ parameters according to Equation (1):

$$
\mathrm{R}_{\mathrm{M}}=\log \left(\frac{1}{\mathrm{R}_{\mathrm{f}}}-1\right)
$$

The $\mathrm{R}_{\mathrm{M}}$ parameter was calculated for every concentration of acetone and extrapolated to zero concentration of organic component in the mobile phase. The chromatographic parameter of lipophilicity $\left(\mathrm{R}_{\mathrm{M} 0}\right)$ was calculated using Equation (2):

$$
\mathrm{R}_{\mathrm{M}}=\mathrm{R}_{\mathrm{M} 0}+b \mathrm{C}
$$

where $C$ is the concentration of acetone in the mobile phase, while $b$ is the slope of the regression plot.

The hydrophobic index $\left(\varphi_{0}\right)$ was determined according to Equation (3):

$$
\varphi_{0}=-\frac{\mathrm{R}_{\mathrm{M} 0}}{b}
$$

\subsection{Theoretical Lipophilicity}

For compounds 1-20, the calculated lipophilicity was determined using various online tools and free available software, including: ALOGPs, AClogP, AlogP, MLOGP, XLOGP2, XLOGP3 (German Research Center for Environmental Health, Neuherberg, Germany), milogP (Molinspiration Cheminformatics, Slovensky Grob, Slovak Republic), iLOGP, WLOGP, and SILICOS-IT (Swiss Institute of Bioinformatics, Lausanne, Switzerland) [38-41]. The pharmacokinetic and physiochemical parameters were determined 
using pKCMS (Bio21 Institute, Melbourne, Australia) and SwissADME software (Swiss Institute of Bioinformatics, Lausanne, Switzerland) [40-43].

\subsection{Structure Optimization}

The optimized chemical structures of compounds 1-16 were calculated using the DFT (B3LYP/6-311G+(d.p)) method implemented in the Gaussian 16 program package [44]. All local minima of energy were confirmed by the absence of an imaginary mode in the vibrational calculations. In our calculations, we applied the basis set of the diffuse function to heavy atoms (+) to obtain a better description of lone pair electrons with orbitals occupying a larger region of space. The obtained optimized structure is presented in Figure S1. The geometries of compounds 1-16 were used to determine the HOMO-LUMO energy, quantum chemical descriptor, the molecular electrostatic potential, and the molecular docking study [45]. All obtained results were visualized using the GaussView, Version 5 software package (Gaussian Inc., Wallingford, CT, USA) [46].

\subsection{Molecular Docking Study}

The three-dimensional (3D) structures (in mol2 format) of the studied compounds were generated using the ChemOffice package (version 19.1, PerkinElmer, Waltham, MA, USA) [47]. Their low-energy conformations were calculated using Gaussian 16 (revision A.03) computer code [44] at the density functional theory (DFT, B3LYP) and 6-311+G(d,p) basis sets. Calculations were performed using the $\mathrm{X}$-ray coordinates of chloroquine as the input structure obtained from the Cambridge Crystallographic Data Centre (CCDC ID: CDMQUI).

Target macromolecule for molecular docking study was obtained from the Protein Data Bank (https: / /www.rcsb.org/, accessed on 1 April 2020). We used the 3D crystal structures of COVID-19 main protein and papain-like protease of SARS CoV-2 (PDB ID: 5R7Z and 6W9C, respectively).

Ligands and proteins used in the calculations were prepared for docking using the AutoDockTools program (Molecular Graphics Laboratory, La Jolla, CA, USA) [48]. In this study, AutoDock Vina [49] tool compiled in PyRx [50] was employed to perform molecular docking. Implementing in AutoDock Vina scoring function was mostly inspired by X-score and combined an empirical free-energy force field with a Lamarckian Genetic Algorithm. The volume was set as $25 \times 25 \times 25 \AA$. The region of interest used for AutoDock Vina docking was fixed as $X=-33,784, Y=20,933, Z=33,306$ for papain-like protease and $X=-11,631, Y=2201, Z=23,194$ for COVID-19 main protein. After calculations, only the nine highest-scored poses were returned as a docking result for ligand-cavity configuration. The complexes obtained in the Vina program were visualized using the BIOVIA Discovery Studio virtual environment (v.17.2.0.16349, Dassault systems, VélizyVillacoublay, France) [51].

\subsection{Correlation and Cluster Analysis}

Based on the experimental and theoretical values of lipophilicity and molecular descriptor values, the correlation and cluster analysis were performed. All data used for the cluster analysis were standardized and the cluster analysis was based on the Euclidean distance. The analysis was carried out using the Statistica 13.1 software (TIBCO Software Inc., Palo Alto, CA, USA).

\section{Results and Discussion}

\subsection{Experimental and Theoretical Lipophilicity}

The hybrids 1-16 and substrates 17-20 were examined under the RP-TLC method. For each compound, the parameter $R_{M}$ was calculated from the retardation factor $\left(R_{f}\right)$ according to Equation (1). Equation (2) was used to determine the $\mathrm{R}_{\mathrm{M} 0}$ and $b$ values and the results are presented in Table 2 . The high correlation coefficients $(r=0.976-0.997)$ for all compounds show good correlation between acetone concentration and $R_{M}$ value. 
Table 2. The experimental values of lipophilicity $\left(\mathrm{R}_{\mathrm{M} 0}\right)$ for compounds 1-20.

\begin{tabular}{ccccc}
\hline Compound & $\mathbf{R}_{\mathbf{M} 0}$ & $\boldsymbol{b}$ & $\mathbf{r}$ & $\mathbf{S D}$ \\
\hline $\mathbf{1}$ & 3.51 & -0.04 & 0.995 & 0.051 \\
$\mathbf{2}$ & 3.64 & -0.04 & 0.992 & 0.067 \\
$\mathbf{3}$ & 3.97 & -0.05 & 0.996 & 0.047 \\
$\mathbf{4}$ & 4.08 & -0.05 & 0.992 & 0.072 \\
$\mathbf{5}$ & 3.56 & -0.04 & 0.983 & 0.100 \\
$\mathbf{6}$ & 3.59 & -0.04 & 0.997 & 0.041 \\
$\mathbf{7}$ & 4.07 & -0.05 & 0.985 & 0.101 \\
$\mathbf{8}$ & 4.24 & -0.05 & 0.993 & 0.065 \\
$\mathbf{9}$ & 3.65 & -0.04 & 0.996 & 0.047 \\
$\mathbf{1 0}$ & 3.77 & -0.04 & 0.996 & 0.048 \\
$\mathbf{1 1}$ & 4.12 & -0.05 & 0.995 & 0.054 \\
$\mathbf{1 2}$ & 4.39 & -0.05 & 0.981 & 0.115 \\
$\mathbf{1 3}$ & 3.78 & -0.04 & 0.998 & 0.028 \\
$\mathbf{1 4}$ & 3.84 & -0.04 & 0.992 & 0.067 \\
$\mathbf{1 5}$ & 4.21 & -0.05 & 0.979 & 0.120 \\
$\mathbf{1 6}$ & 4.58 & -0.05 & 0.960 & 0.183 \\
$\mathbf{1 7}$ & 4.40 & -0.05 & 0.995 & 0.065 \\
$\mathbf{1 8}$ & 4.54 & -0.05 & 0.989 & 0.098 \\
$\mathbf{1 9}$ & 5.07 & -0.06 & 0.995 & 0.073 \\
$\mathbf{2 0}$ & 5.26 & -0.06 & 0.976 & 0.161 \\
\hline
\end{tabular}

$b$ is the slope, $r$ is the correlation coefficient, and SD is the standard deviation for the linear relationship $R_{M}=R_{M 0}+b C$.

The calibration curve is required for the conversion of $\mathrm{R}_{\mathrm{M} 0}$ to $\log \mathrm{P}_{\mathrm{TLC}}$. The following compounds were used as standard substances: acetanilide, prednisone, 4-bromoacetophenone, benzophenone, anthracene, dibenzyl, 9-phenylanthracene, and dichlorodiphenyltrichloroethane (DDT), for which the literature values of $\log \mathrm{P}_{\text {lit }}$ are in the range 1.21-6.38 [52,53]. The $\mathrm{R}_{\mathrm{M} 0}$ for the standard substance was determined in the same conditions as for compounds 1-20 (Table 3).

Table 3. The experimental $\left(\mathrm{R}_{\mathrm{M} 0}\right)$ and literature $\left(\log \mathrm{P}_{\text {lit }}\right)$ lipophilicity values of standard substance.

\begin{tabular}{|c|c|c|c|c|c|c|}
\hline Compound & $\log P_{\text {lit }}$ & $\mathbf{R}_{\mathbf{M} 0}$ & $b$ & $\mathbf{r}$ & SD & $\log P_{\text {TLC }}$ \\
\hline Acetanilide & 1.21 & 0.55 & -0.01 & 0.954 & 0.051 & 1.19 \\
\hline Prednisone & 1.63 & 0.73 & -0.02 & 0.932 & 0.077 & 1.39 \\
\hline 4-Bromoacetophenone & 2.43 & 1.89 & -0.03 & 0.993 & 0.037 & 2.72 \\
\hline Benzophenone & 3.18 & 2.37 & -0.03 & 0.993 & 0.046 & 3.26 \\
\hline Anthracene & 4.45 & 3.48 & -0.04 & 0.994 & 0.053 & 4.52 \\
\hline Dibenzyl & 4.79 & 3.65 & -0.04 & 0.997 & 0.043 & 4.72 \\
\hline DDT & 6.01 & 4.87 & -0.06 & 0.985 & 0.041 & 6.17 \\
\hline 9-Phenylanthracene & 6.38 & 4.93 & -0.06 & 0.993 & 0.080 & 6.11 \\
\hline
\end{tabular}

$b$ is the slope, $r$ is the correlation coefficient and $\mathrm{SD}$ is the standard deviation for the linear relationship $\mathrm{R}_{\mathrm{M}}=\mathrm{R}_{\mathrm{M} 0}+b \mathrm{C}$.

The calibration curve Equation (4) was determined by linear correlation between the $\log \mathrm{P}_{\text {lit }}$ and $\mathrm{R}_{\mathrm{M}}$.

$$
\log \mathrm{P}_{\mathrm{TLC}}=1.139 \mathrm{R}_{\mathrm{M} 0}+0.561(\mathrm{r}=0.996 ; \mathrm{SD}=0.188)
$$

For the standard substances the $\log \mathrm{P}_{\mathrm{TLC}}$ was calculated according to the calibration curve (Equation (4)). Figure S2 shows a good agreement between experimental and literature values of lipophilicity $(\mathrm{r}=0.996)$.

Equations (3) and (4) were used to determine the $\log \mathrm{P}_{\mathrm{TLC}}$ and the hydrophobic index $\left(\varphi_{0}\right)$, respectively. The results are presented in Figure 2 and Table S1. 


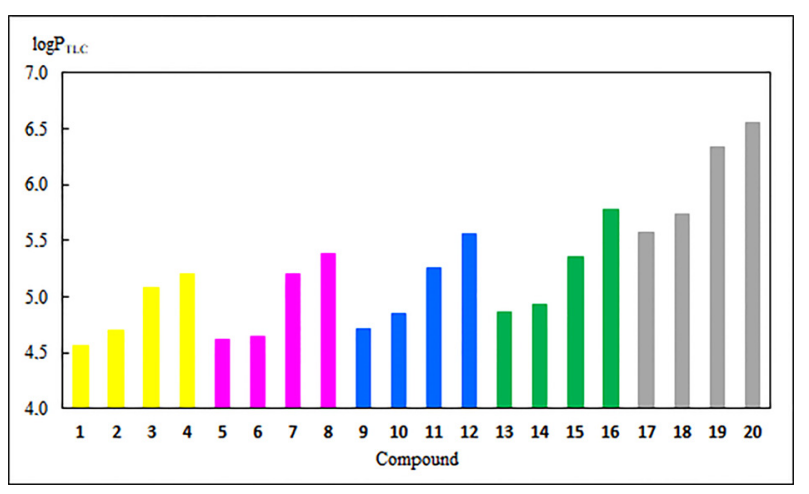

(a)

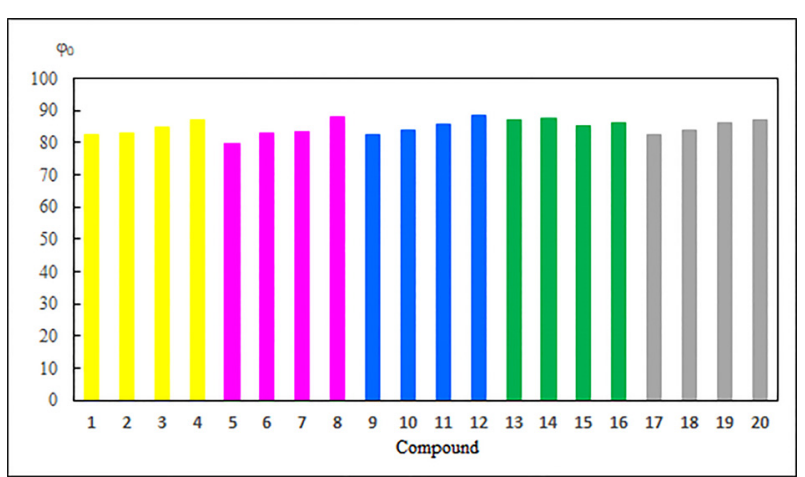

(b)

Figure 2. The experimental values of (a) lipophilicity $\left(\log \mathrm{P}_{\mathrm{TLC}}\right)$ and $(\mathbf{b})$ hydrophobic index $\left(\varphi_{0}\right)$ for 5,8 -quinolinedione 1-4 (yellow), 5,8-isoquinoline 5-8 (violet), 2-methylo-5,8-quinolinedione 9-12 (blue), 1,4-naphthoquinone 13-16 (green) derivatives, and substrate 17-20 (grey).

For compounds 1-20, lipophilicity is in the range of 4.56-6.55. For a series of compounds 17-20, the lipophilicity depends on the type of group at the C-3 position of the betulin moiety. Derivatives with hydroxyl (17) or oxo (18) groups at this position exhibit comparable values of $\log \mathrm{P}_{\mathrm{TLC}}$. Replacement of the hydroxyl group by acyl substituents (19 and 20) causes an increase in lipophilicity.

Comparing the $\log \mathrm{P}_{\mathrm{TLC}}$ for hybrids 1-16 and derivatives 17-20 shows that introduction of the 1,4-quinone fragment to the betulin moiety reduces the lipophilicity. The lipophilicity depends on the type of 1,4-quinone moiety and the order is as follows: 5,8quinolinedione (1-4) > 5,8-isoquinolinedione (5-8) > 2-methyl-5,8-quinolinedione (9-12) > 1,4-naphthoquinone (13-16).

Comparing the lipophilicity of compounds 1-16 shows that the type of substituent at the $\mathrm{C}-3$ position of betulin moiety influences the lipophilicity, and the order is as follows: hydroxy $(1,5,9$, and 13$)>$ oxo $(2,6,10$, and 14) $>$ ethanoyl $(3,7,11$, and 15) $>$ propanoyl $(4,8,12$, and 16).

The hydrophobic indexes for hybrids 1-16 and compounds 17-20 are in the ranges of 79.81-88.21 and 82.62-87.13, respectively. A higher value of $\varphi_{0}$ means that compounds 1-20 are less soluble in water. Comparing the hydrophobicity of derivatives 1-16 and 17-20 shows that the introduction of 1,4-quinone moiety slightly affects the solubility in water. In the series of 1-16, no relationship between the type of 1,4-qinone moiety and hydrophobicity index has been observed.

Theoretical values of lipophilicity were determined with the available programs [38-41]. The calculated values of $\log \mathrm{P}$ cover a wide range from 4.11 to 12.19 depending on the mathematical module used by programs. The theoretical results are presented in Figure 3 and Table S2.

For 1-20, all programs show that lipophilicity depends on the type of substituent at the C-3 position of the betulin moiety, and this correlation is consistent with the experimental results. As shown in Figure 3, compounds 17-20 have lower lipophilicity than hybrids 1-16, which is not in agreement with the experimental results. The exception is the MLOGP program, for which the theoretical lipophilicity for derivatives 17-20 are similar to the experimental values (Table S2). Comparing the $\log P$ values for 1-16 shows that the theoretical lipophilicity slightly depends on the type of 1,4-quinone moiety. Moreover, hybrids with 5,8-quinolinedione (1-4) and 5,8-isoquinolinedione (5-8) moiety have the same molecular formula. In this case, atomistic (WLOGP) and topological (MOLGP and SILCOSIT) methods exhibit the same value of lipophilicity, but the $\operatorname{LogP}_{\mathrm{TLC}}$ is different. For this reason, to better predict the lipophilicity, it is important to find a correlation between its experimental and theoretical values. Due to the structural differences of hybrids 1-16 and betulin derivatives 17-20, separate equations were developed for these two groups of compounds (Table 4). 


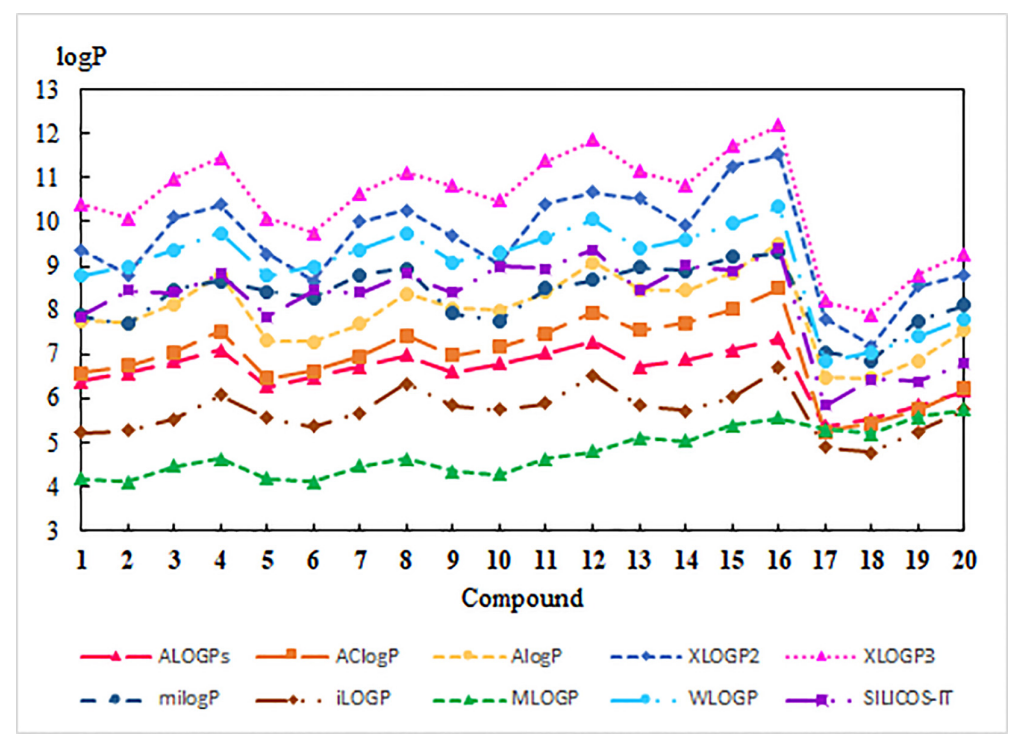

Figure 3. The profile of changes for theoretical lipophilicity for compounds 1-20.

Table 4. Correlation equations for experimental $\left(\log P_{T L C}\right)$ and theoretical $\left(\log P_{\text {calc }}\right)$ values of lipophilicity for compounds 1-16 and 17-20.

\begin{tabular}{|c|c|c|c|}
\hline Program & Correlation Equation & $\mathbf{r}$ & SD \\
\hline \multicolumn{4}{|c|}{ Compounds 1-16 } \\
\hline ALOGPs & $\log P_{\mathrm{TLC}}=1.094 \log \mathrm{P}_{\mathrm{CALC}}-2.416$ & 0.932 & 0.137 \\
\hline $\mathrm{AC} \log \mathrm{P}$ & $\log P_{\mathrm{TLC}}=0.540 \log \mathrm{P}_{\mathrm{CALC}}+1.104$ & 0.854 & 0.196 \\
\hline $\mathrm{A} \log \mathrm{P}$ & $\log P_{\mathrm{TLC}}=0.492 \log \mathrm{P}_{\mathrm{CALC}}+0.987$ & 0.843 & 0.203 \\
\hline XLOGP2 & $\log \mathrm{P}_{\mathrm{TLC}}=0.378 \log \mathrm{P}_{\mathrm{CALC}}+1.268$ & 0.854 & 0.196 \\
\hline XLOGP3 & $\log \mathrm{P}_{\mathrm{TLC}}=0.472 \log \mathrm{P}_{\mathrm{CALC}}-0.121$ & 0.887 & 0.174 \\
\hline milogP & $\log P_{\mathrm{TLC}}=0.527 \log \mathrm{P}_{\mathrm{CALC}}+0.549$ & 0.729 & 0.258 \\
\hline iLOGP & $\log P_{\mathrm{TLC}}=0.758 \log \mathrm{P}_{\mathrm{CALC}}+0.620$ & 0.887 & 0.174 \\
\hline WLOGP & $\log \mathrm{P}_{\mathrm{TLC}}=0.755 \log \mathrm{P}_{\mathrm{CALC}}-2.091$ & 0.953 & 0.114 \\
\hline MLOGP & $\log P_{\mathrm{TLC}}=0.582 \log \mathrm{P}_{\mathrm{CALC}}+2.353$ & 0.723 & 0.260 \\
\hline SILICOS-IT & $\begin{array}{r}\log P_{\text {TLC }}=0.634 \log P_{\text {CALC }}-0.443 \\
\text { Compounds }\end{array}$ & 0.798 & 0.227 \\
\hline ALOGPs & $\log P_{\mathrm{TLC}}=1.313 \log \mathrm{P}_{\mathrm{CALC}}-1.485$ & 0.980 & 0.114 \\
\hline $\mathrm{AClog} \mathrm{P}$ & $\log P_{\mathrm{TLC}}=1.078 \log \mathrm{P}_{\mathrm{CALC}}-0.058$ & 0.962 & 0.157 \\
\hline $\mathrm{A} \log \mathrm{P}$ & $\log P_{\mathrm{TLC}}=0.847 \log \mathrm{P}_{\mathrm{CALC}}+0.251$ & 0.962 & 0.232 \\
\hline XLOGP2 & $\log P_{\mathrm{TLC}}=0.567 \log \mathrm{P}_{\mathrm{CALC}}+1.462$ & 0.880 & 0.273 \\
\hline XLOGP3 & $\log P_{\mathrm{TLC}}=0.718 \log \mathrm{P}_{\mathrm{CALC}}-0.097$ & 0.929 & 0.213 \\
\hline milogP & $\log P_{\mathrm{TLC}}=0.766 \log \mathrm{P}_{\mathrm{CALC}}+0.345$ & 0.960 & 0.160 \\
\hline iLOGP & $\log P_{\mathrm{TLC}}=0.994 \log \mathrm{P}_{\mathrm{CALC}}+0.916$ & 0.924 & 0.220 \\
\hline WLOGP & $\log P_{\mathrm{TLC}}=1.083 \log \mathrm{P}_{\mathrm{CALC}}-1.828$ & 0.979 & 0.116 \\
\hline MLOGP & $\log P_{\mathrm{TLC}}=1.754 \log \mathrm{P}_{\mathrm{CALC}}-3.543$ & 0.955 & 0.170 \\
\hline SILICOS-IT & $\log P_{\mathrm{TLC}}=0.965 \log \mathrm{P}_{\mathrm{CALC}}-0.092$ & 0.815 & 0.332 \\
\hline
\end{tabular}

The relationship between the lipophilicity and structure of compounds 1-20 was analyzed by cluster analysis (Figure 4).

As shown in Figure 4, compounds 1-20 are arranged in two main clusters. The first cluster consists of betulin derivatives 17-20 and the second one of hybrids 1-16. The high value of Euclidean distance between two clusters suggests that there is a low correlation between structures of these two groups of compounds.

The second cluster can be divided into four subclusters. In the first subcluster, the hybrids are arranged according to the type of betulin moiety, which means that they have oxo group at the C-3 position of the betulin moiety. The second and third subclusters consist of 1,4-naphthoquinone $(\mathbf{1 3}, \mathbf{1 5}$, and 16) and 5,8-quinolinedione moiety $(5,7$, and 8), respectively. Compounds containing the 5,8-quinolinedione (1, 3, and 4) and 2-methyl-5,8- 
quinolinedione $(\mathbf{9}, \mathbf{1 1}$, and $\mathbf{1 2})$ are included into the subcluster four. The similarity analysis shows a strong correlation between lipophilicity and structure of hybrids 1-16.

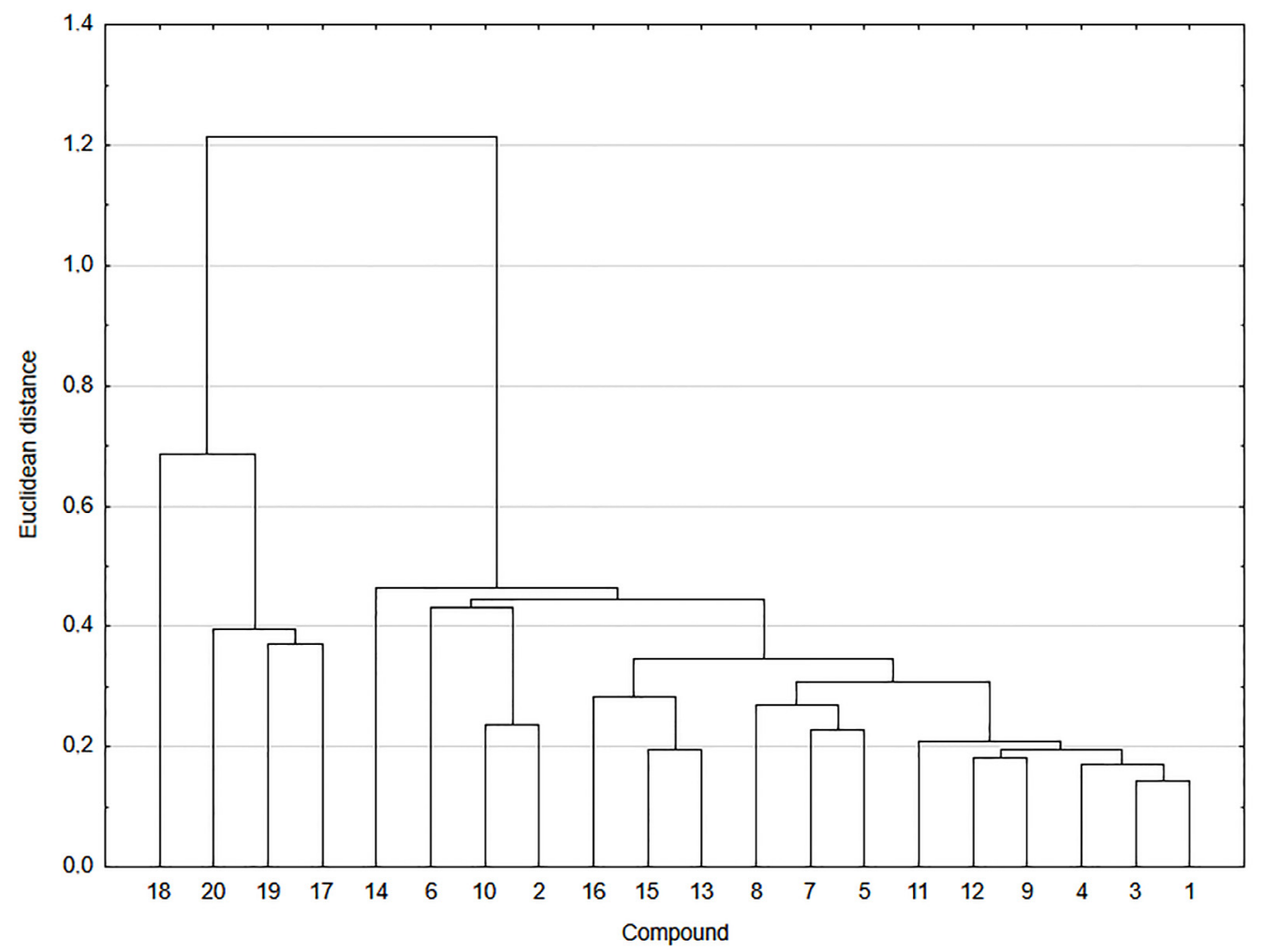

Figure 4. Similarity analysis of the experimental and theoretical values of lipophilicity for compounds 1-20.

\subsection{Physicochemical and Pharmacokinetic Properties}

In the early drug discovery process, one of the important stages is to optimize the physicochemical properties of a potential drug. Based on the observation of the physicochemical properties of oral drugs, Lipinski formulated the Rule of Five. According to this rule, the lipophilicity $(\log \mathrm{P})$, molecular weight $(\mathrm{MW})$, number of acceptors (HA), and donors (HD) of hydrogen bond should be a multiple of five [54]. In an attempt to improve the prediction of bioavailability, the rules were expanded by Veber to the number of rotatable bonds (RB) and topological polar surface area (TPSA) are also determined $[55,56]$. The molecular descriptors for tested hybrids 1-16 are presented in Table 5.

The tested hybrids 1-16 have a molecular mass above $500 \mathrm{~g} / \mathrm{mol}$, which means they do not meet the mass criterion. All compounds have less than five hydrogen bond donors $(\mathrm{HD}=0-1)$. The 5,8-quinolinedione and 5,8-isoquinolinedione derivatives with hydroxyl and oxo groups at C-3 position of betulin (1-2, 5-6, and 9-10) have less than 10 hydrogen bond acceptors $(\mathrm{HA}=9-10)$ and the $\log \mathrm{P}_{\mathrm{TLC}}$ less than 5 , which means that these compounds meet three of four Lipinski rules. Only compounds with propanoyl substituents at the $C-3$ position of the betulin moiety $(4,8,12$, and 16) do not meet the Veber's rules concerning the number of rotatable bonds $(\mathrm{RB}<10)$. The TPSA for $\mathbf{1 - 1 6}$ is less than $140 \AA$, which determines the oral bioavailability.

For compounds 1-16, the relationship between the type of 1,4-quinone moiety, the physicochemical parameters and experimental lipophilicity was analyzed by means of a dendrogram (Figure 5). 
Table 5. Molecular descriptors for hybrids 1-16.

\begin{tabular}{cccccc}
\hline Compound & MW (g/mol) & HA & HD & RB & TPSA (̊̊) \\
\hline $\mathbf{1}$ & 787.42 & 10 & 1 & 9 & 133.50 \\
$\mathbf{2}$ & 785.41 & 10 & 0 & 9 & 130.34 \\
$\mathbf{3}$ & 829.46 & 11 & 0 & 10 & 139.57 \\
$\mathbf{4}$ & 843.49 & 11 & 0 & 11 & 139.57 \\
$\mathbf{5}$ & 787.42 & 10 & 1 & 9 & 133.50 \\
$\mathbf{6}$ & 785.41 & 10 & 0 & 9 & 130.45 \\
$\mathbf{7}$ & 829.46 & 11 & 0 & 10 & 139.57 \\
$\mathbf{8}$ & 843.39 & 11 & 0 & 11 & 139.57 \\
$\mathbf{9}$ & 801.45 & 10 & 1 & 9 & 133.50 \\
$\mathbf{1 0}$ & 799.43 & 10 & 0 & 9 & 130.34 \\
$\mathbf{1 1}$ & 843.49 & 11 & 0 & 10 & 139.57 \\
$\mathbf{1 2}$ & 857.51 & 11 & 0 & 11 & 139.57 \\
$\mathbf{1 3}$ & 786.44 & 9 & 1 & 9 & 120.61 \\
$\mathbf{1 4}$ & 784.42 & 9 & 0 & 9 & 117.45 \\
$\mathbf{1 5}$ & 828.47 & 10 & 0 & 10 & 126.68 \\
$\mathbf{1 6}$ & 842.50 & 10 & 0 & 11 & 126.68 \\
\hline
\end{tabular}

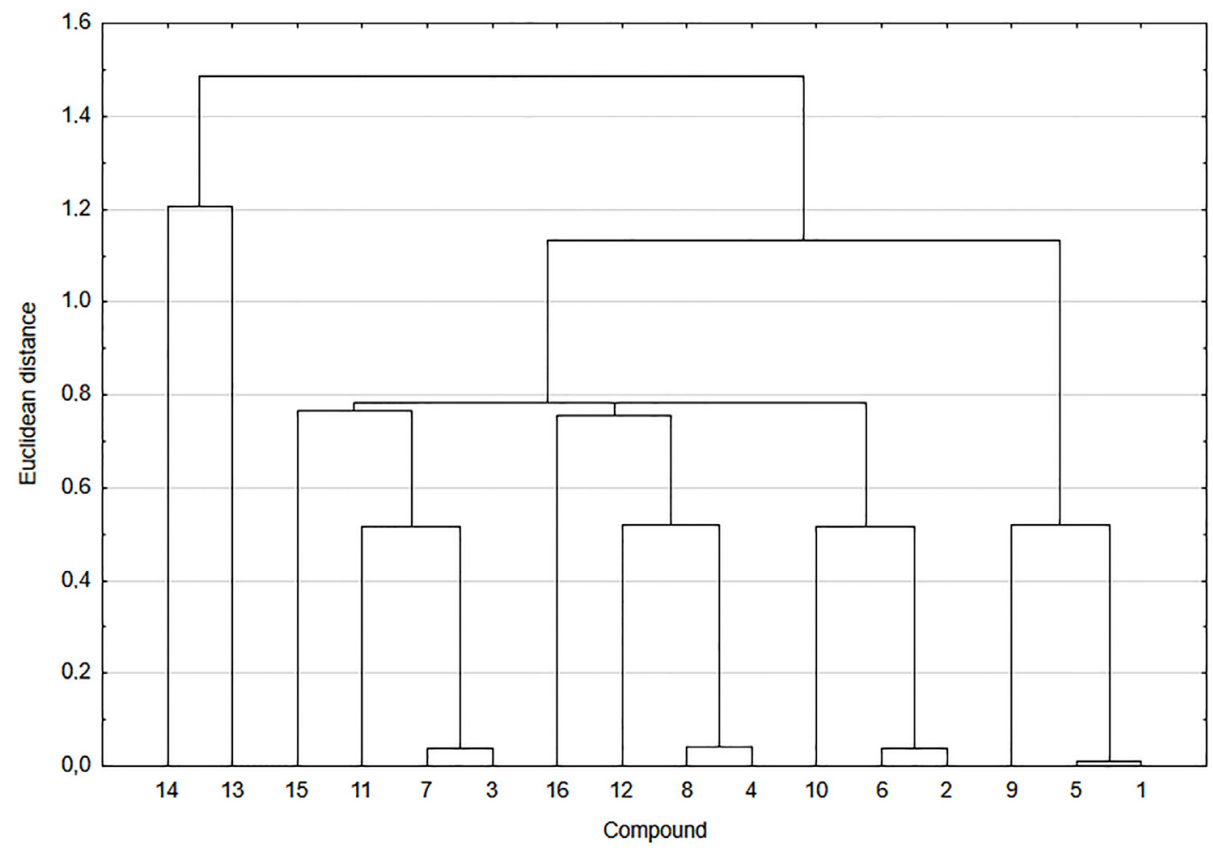

Figure 5. Similarity analysis of the physicochemical parameters and the experimental lipophilicity for compounds 1-16.

The similarity analysis shows two main clusters. The first cluster consists of 1,4naphthoquinone derivatives (13 and 14) and the second one is divided into four subclusters. Analysis of subclusters show that compounds with the 5,8-quinolinedione (1-4) and 2methyl-5,8-quinolinedione (5-8) exhibit similar properties. Comparing the properties of 5,8-quinolinedione (1-4) and 5,8-isoquinolinedione (9-11) shows that the position of nitrogen atom in heterocyclic ring influences their physicochemical parameters. The similarity analysis shows that nitrogen atom significantly affects properties of the tested derivatives.

The multilinear regression (MLR) Equation (5) expresses the relationship between the experimental lipophilicity $\left(\log \mathrm{P}_{\mathrm{TLC}}\right)$ and physicochemical parameters, such as molecular mass (MW), topological polar surface (TPSA), and number of rotatable bonds (RB).

$$
\begin{gathered}
\log \mathrm{P}_{\mathrm{TLC}}=0.992 \mathrm{MW}-0.488 \mathrm{TPSA}+0.213 \mathrm{RB}-3.362 \\
\left(\mathrm{r}=0.985, \mathrm{r}^{2}=0.969, \mathrm{SD}=1.11, \mathrm{VIF}=3.12, F=126.7\right)
\end{gathered}
$$


The correlation coefficient shows good agreement between physicochemical parameters and experimental lipophilicity. A comparison of the experimental and calculated parameters for the investigated compounds are shown in Table S3. The result shows that lipophilicity could be determined by in silico parameters.

The physicochemical properties were used to in silico calculate the pharmacokinetic parameters, which determine the absorption of the potential drug [57]. The prediction of oral and transdermal absorption was performed in silico using the Caco-2 cell (logPapp), human intestinal absorption (HIA), and skin permeability $(\log \mathrm{Kp})$ models. Moreover, the neurotoxicity of the compounds can be designated by blood-brain barrier permeability $(\log \mathrm{BB})$ and central nervous system $(\log P S)$ penetration $[12,58-60]$. The pharmacokinetic parameters of compounds 1-16 have been determined in silico by pkCSM software and they are presented in Table 6.

Table 6. Pharmacokinetic parameters of hybrids 1-16.

\begin{tabular}{cccccc}
\hline Compound & logBB & logPS & logKp & $\operatorname{logPapp}$ & HIA \\
\hline $\mathbf{1}$ & -1.459 & -2.481 & -2.734 & 0.641 & 97.226 \\
$\mathbf{2}$ & -1.581 & -2.513 & -2.735 & 0.639 & 98.193 \\
$\mathbf{3}$ & -1.804 & -2.442 & -2.735 & 0.195 & 98.510 \\
$\mathbf{4}$ & -1.831 & -2.434 & -2.735 & 0.215 & 98.358 \\
$\mathbf{5}$ & -1.457 & -2.466 & -2.735 & 0.672 & 97.226 \\
$\mathbf{6}$ & -1.579 & -2.499 & -2.735 & 0.671 & 98.193 \\
$\mathbf{7}$ & -1.802 & -2.428 & -2.735 & 0.158 & 98.510 \\
$\mathbf{8}$ & -1.830 & -2.420 & -2.735 & 0.178 & 98.358 \\
$\mathbf{9}$ & -1.447 & -2.443 & -2.734 & 0.598 & 97.235 \\
$\mathbf{1 0}$ & -1.569 & -2.475 & -2.735 & 0.597 & 98.090 \\
$\mathbf{1 1}$ & -1.792 & -2.404 & -2.735 & 0.181 & 98.358 \\
$\mathbf{1 2}$ & -1.820 & -2.396 & -2.735 & 0.200 & 98.231 \\
$\mathbf{1 3}$ & -1.219 & -2.215 & -2.734 & 0.747 & 97.410 \\
$\mathbf{1 4}$ & -1.341 & -2.248 & -2.735 & 0.745 & 97.838 \\
$\mathbf{1 5}$ & -1.564 & -2.177 & -2.735 & 0.733 & 97.885 \\
$\mathbf{1 6}$ & -1.592 & -2.169 & -2.735 & 0.728 & 97.879 \\
\hline
\end{tabular}

According to the model used in the pkCMS software, if logPapp is more than 0.9, it means that the compound expresses the high Caco-2 permeability [42]. For the tested hybrids 1-12, the logPapp value is in the range 0.200-0.672, which means moderate Caco-2 permeability. In the series of 5,8-quinolinedione hybrids (1-12), compounds with hydroxyl or oxo groups at the C-3 position of betulin moiety $(\mathbf{1}-\mathbf{2}, \mathbf{5}-\mathbf{6}, \mathbf{9}-\mathbf{1 0})$ have higher values of logPapp than hybrids with acyl group at this position (3-4, 7-8, 11-12). In the group of 1,4-naphthoquinone compounds (13-16), the Caco-2 permeability does not depend on the type of substituent at the C-3 position of the betulin moiety. Comparing the logPapp values shows that the permeability depends on the type of 1,4-quinone moiety and the following order is fulfilled: 1,4-naphthoquinone $>$ 5,8-quinolinedione $>2$-metyl-5,8-quionolinedione $>$ 5,8-isoquinolnedione. For $\mathbf{1 - 1 6}$ the human intestinal absorption (HIA) are in the range of (97.226-98.510), which are considered to be high. The HIA index slightly depends on the type of 1,4-quinonemoiety. Hybrids 1-16 have a moderate skin permeability because they have the logKp lower than -2.5 .

For 1-16, the $\log B B$ are lower than -1 , which means these hybrids poorly cross the brain-blood barrier. Compounds do not pass into the central nervous system when the $\log P S$ is less than -2 . This result shows that the tested derivatives 1-16 are not neurotoxic.

The similarity analysis showed no correlation between pharmacokinetic parameters and the structure of compounds 1-16 (Figure S3). However, the cluster analysis showed that only betulin moiety influences the pharmacokinetic parameters of hybrids. 


\subsection{Molecular Properties}

The energy of HOMO and LUMO orbitals determines the ability of the molecule to donated or receive an electron. The energy of orbitals can be used to calculate the global reactivity descriptors, such as: ionization potential (I), electron affinity (A), hardness $(\eta)$, chemical potential $(\mu)$, electronegativity $(\chi)$, and electrophilicity index $(\omega)$ [61].

The HOMO and LUMO orbitals of 1-16 are presented in Figure S4. Table 7 shows the $\mathrm{HOMO}$ and LUMO energy, the energy gap $\left(\triangle \mathrm{E}=\mathrm{E}_{\mathrm{HOMO}}-\mathrm{E}_{\mathrm{LUMO}}\right)$, the global reactivity descriptors, and dipole moment (DM).

Table 7. Electrostatic descriptor of hybrids 1-16.

\begin{tabular}{|c|c|c|c|c|c|c|c|c|c|c|}
\hline Hybrid & $\begin{array}{c}\mathrm{E}_{\text {номо }} \\
\text { (kcal/mol) }\end{array}$ & $\begin{array}{c}\text { E }_{\text {LUMO }} \\
\text { (kcal/mol) }\end{array}$ & $\begin{array}{c}\Delta \mathrm{E} \\
(\mathrm{kcal} / \mathrm{mol})\end{array}$ & $\begin{array}{c}\mathrm{I} \\
(\mathrm{kcal} / \mathrm{mol})\end{array}$ & $\begin{array}{c}\mathrm{A} \\
\text { (kcal/mol) }\end{array}$ & $\underset{\text { (kcal/mol) }}{\eta}$ & $\begin{array}{c}\mu \\
\text { (kcal/mol) }\end{array}$ & $\begin{array}{c}\chi \\
\text { (kcal/mol) }\end{array}$ & $\underset{(\mathrm{kcal} / \mathrm{mol})}{\omega}$ & DM (D) \\
\hline 1 & -6.227 & -3.918 & -2.310 & 6.227 & 3.918 & 1.155 & -5.073 & 5.073 & 11.140 & 5.6507 \\
\hline 2 & -6.510 & -3.989 & -2.521 & 6.510 & 3.989 & 1.261 & -5.250 & 5.250 & 10.930 & 9.563 \\
\hline 3 & -6.423 & -3.980 & -2.443 & 6.423 & 3.980 & 1.222 & -5.202 & 5.202 & 11.076 & 6.3035 \\
\hline 4 & -6.422 & -3.984 & -2.438 & 6.422 & 3.984 & 1.219 & -5.203 & 5.203 & 11.106 & 6.5282 \\
\hline 5 & -6.503 & -3.816 & -2.687 & 6.503 & 3.816 & 1.344 & -5.159 & 5.159 & 9.906 & 5.8305 \\
\hline 6 & -6.228 & -3.869 & -2.360 & 6.228 & 3.869 & 1.180 & -5.049 & 5.049 & 10.801 & 8.9646 \\
\hline 7 & -6.421 & -3.867 & -2.554 & 6.421 & 3.867 & 1.277 & -5.144 & 5.144 & 10.359 & 6.548 \\
\hline 8 & -6.426 & -3.866 & -2.560 & 6.426 & 3.866 & 1.280 & -5.146 & 5.146 & 10.345 & 6.4041 \\
\hline 9 & -6.499 & -4.151 & -2.348 & 6.499 & 4.151 & 1.174 & -5.325 & 5.325 & 12.078 & 6.7295 \\
\hline 10 & -6.248 & -4.183 & -2.065 & 6.248 & 4.183 & 1.032 & -5.216 & 5.216 & 13.176 & 7.2985 \\
\hline 11 & -6.450 & -4.162 & -2.288 & 6.450 & 4.162 & 1.144 & -5.306 & 5.306 & 12.306 & 4.5204 \\
\hline 12 & -6.450 & -4.165 & -2.285 & 6.450 & 4.165 & 1.142 & -5.307 & 5.307 & 12.328 & 4.6037 \\
\hline 13 & -6.485 & -3.786 & -2.699 & 6.485 & 3.786 & 1.349 & -5.135 & 5.135 & 9.772 & 7.0345 \\
\hline 14 & -6.239 & -3.816 & -2.424 & 6.239 & 3.816 & 1.212 & -5.027 & 5.027 & 10.428 & 8.3989 \\
\hline 15 & -6.428 & -3.792 & -2.637 & 6.428 & 3.792 & 1.318 & -5.110 & 5.110 & 9.903 & 5.0970 \\
\hline 16 & -6.442 & -3.793 & -2.649 & 6.442 & 3.793 & 1.325 & -5.117 & 5.117 & 9.885 & 5.6097 \\
\hline
\end{tabular}

For all compounds 1-16, the LUMO orbitals are mainly delocalized at the 1,4-quinone moiety. Localization of HOMO orbitals depends on the type of substituent at the C-3 position of the betulin moiety. The HOMO orbitals of hybrids with hydroxy and acyl groups $(1,3-5,7-9,11-13$, and 15-16) at the C-3 position are mainly delocalized at the isopropenyl group and A ring of betulin. For hybrids with the oxo group $(\mathbf{2}, \mathbf{6}, \mathbf{1 0}$, and 14), these orbitals are delocalized at the D ring and oxo group (Figure S4). The molecular properties influence the reactivity and stability of molecules. The high value of $\mathrm{E}_{\mathrm{HOMO}}$ and low value of $E_{L U M O}$ show that the compounds are highly reactive with nucleophilic molecules. The energy gap $\Delta \mathrm{E}$ depends on the van der Waals interaction between molecules and its value could be correlated with the biological activity of the compounds $[62,63]$. The hybrids 1, 5, 9, and 13 are characterized by the lowest chemical hardness and the highest negative value of chemical potential, which means they are comparatively soft with high polarizability compared with other compounds in this series.

The arrangement of nucleophilic and electrophilic regions of a molecule influences its interaction with a biological target through hydrogen bonds and hydrophobic interactions. The distribution of the positive and negative charges of molecule is described by the molecular electrostatic potential map (MEP) [64,65]. The different charges are represented by different colors, which means that the red, blue, and green areas are negative, positive, or neutral, respectively [66]. The MEP's are sketched for an order of $(-47,935)$ to $47,935 \mathrm{kcal} / \mathrm{mol}$. The maps for hybrids 1, 5, 9, and 13 present in Figure 6, while for the rest of the compounds, they are shown in Figure S5.

For all hybrids 1-16, the nucleophilic regions (red color) are localized in four main area. The first and second areas are localized on 1,4-quinone moiety. The first area contains the carbonyl atom at C-5 and the second area the carbonyl group at C-8, and the nitrogen atom. The third area includes the triazole linker, and the fourth, the substituent at the C-3 position of the betulin moiety. The electrophilic regions (blue color) are localized near the methine group at 1,4-quinone moiety and the methylene group at the triazole linker, while the betulin regions are neutral (Figure 6 and Figure S5). 


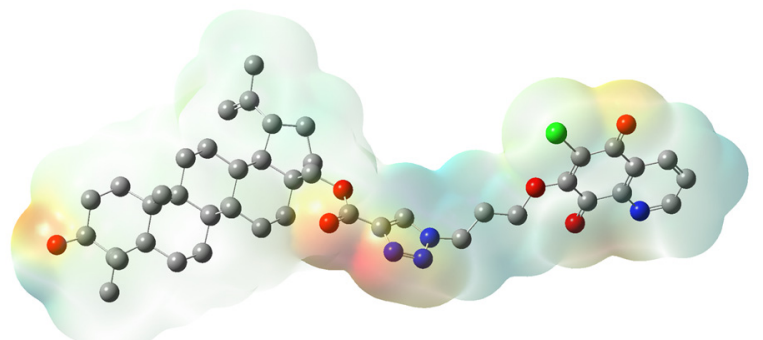

(a)

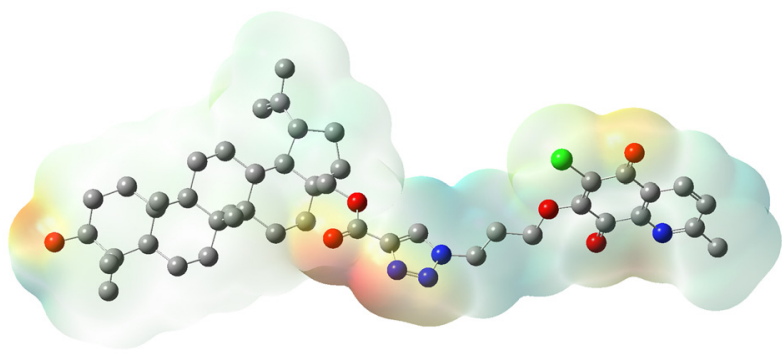

(c)

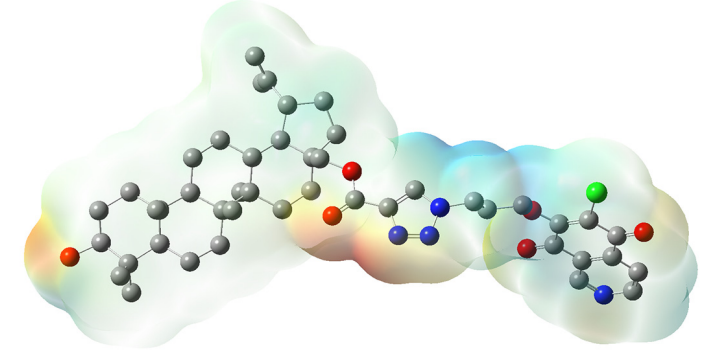

(b)

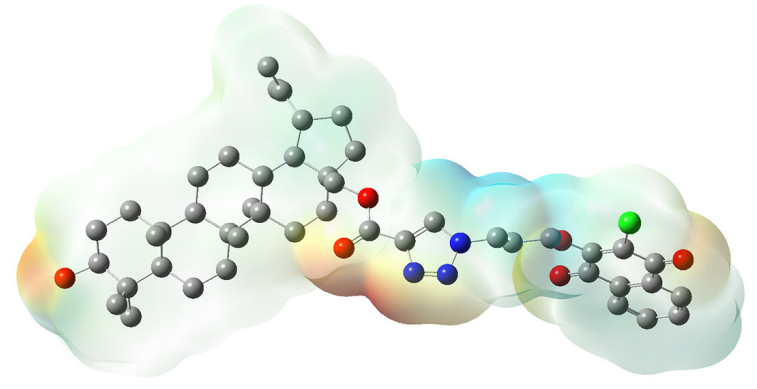

(d)

Figure 6. Molecular electrostatic potential plotted for hybrids: (a) 1, (b) 5, (c) 9, and (d) 13.

In each area, the local minima have been determined for 1-16, and they are collected in Table S4. The analysis of the local minima in the first, third, and fourth areas show that the arrangement of charges does not depend on the type of 1,4-quinone moiety. However, in the second area, the amount of potential minima depends on the type of 1,4-quinone moiety, i.e., the hybrids with 5,8-quinolinedione or 5,8-isoquinolinedione moiety have two potential minima, but compounds with 1,4-naphthoquinone moiety have only one potential minima in this area (Table S4).

\subsection{Molecular Docking Study}

Since the end of 2019, coronavirus disease 2019 (COVID-19), caused by SARS-CoV2 , has infected many people around the word. The World Health Organization (WHO) estimated that up to April 2021 more than 142 million people tested positive for COVID19 and more than 3 million people died from this virus [67]. At the beginning of the pandemic, attempts were made to treat with chloroquine, but this treatment was halted and now chloroquine is not recommended (Figure 6) [68]. Contemporary reports indicate the effective use of amantadine and remdesivir in the treatment of patients with SARS-CoV-2 (Figure 7) $[69,70]$.<smiles>CCN(CC)CCCC(C)Nc1ccnc2cc(Cl)ccc12</smiles><smiles>CCC(CC)COC(=O)C(C)N[P+]([O-])(OCC1O[C@](C#N)(c2ccc3c(N)ncnn23)[C@H](O)[C@@H]1O)Oc1ccccc1</smiles><smiles>NC12CC3CC(CC(C3)C1)C2</smiles>

Figure 7. Chemical structure of drugs used in COVID-19 treatment.

Continuing our research on molecular docking to SARS-CoV-2 targets, we examined the interaction between hybrids 1-16 and Mpro and PLpro proteins using the AutoDock Vina program (referred to as Vina). As reference ligands, chloroquine, amantadine, and remdesivir were used (Figure 7 ). 
The results obtained with the use of the Vina program are presented in Table 8. The lower the $\Delta G$ energy, the better the affinity of the tested ligands for the receptor. Calculations of the $\mathrm{K}_{\mathrm{i}}$ from the binding energy of the pose generated by Vina were performed using Equations (6) and (7).

$$
\begin{aligned}
& \frac{\Delta \mathrm{G}}{\mathrm{R} \cdot \mathrm{T}}=\ln \mathrm{K}_{\mathrm{i}}(\text { for } \mathrm{T}\left.=298 \mathrm{~K} \text { and } \mathrm{R}=1.987\left[\frac{\mathrm{kcal}}{\mathrm{K} \cdot \mathrm{mol}}\right]\right), \\
& \mathrm{K}_{\mathrm{i}}=\exp \left(\frac{\Delta \mathrm{G}}{\mathrm{R} \cdot \mathrm{T}}\right) .
\end{aligned}
$$

\begin{tabular}{|c|c|c|c|c|c|c|c|c|c|}
\hline \multirow{2}{*}{ Compound } & \multicolumn{2}{|c|}{ Mpro } & \multicolumn{2}{|c|}{ PLpro } & \multirow{2}{*}{ Compound } & \multicolumn{2}{|c|}{ Mpro } & \multicolumn{2}{|c|}{ PLpro } \\
\hline & $\Delta \mathrm{G}$ & $\mathrm{pK}_{\mathrm{I}}$ & $\Delta \mathrm{G}$ & $\mathrm{pK}_{\mathrm{I}}$ & & $\Delta \mathrm{G}$ & $\mathrm{pK}_{\mathrm{I}}$ & $\Delta \mathrm{G}$ & $\mathrm{pK}_{\mathrm{I}}$ \\
\hline 1 & -8.8 & 6.46 & -8.3 & 6.09 & 11 & -9.3 & 6.82 & -6.4 & 4.70 \\
\hline 2 & -8.9 & 6.53 & -6.9 & 5.06 & 12 & -9.1 & 6.68 & -7.0 & 5.14 \\
\hline 3 & -8.6 & 6.31 & -6.5 & 4.77 & 13 & -8.6 & 6.31 & -7.6 & 5.58 \\
\hline 4 & -7.8 & 5.72 & -6.5 & 4.77 & 14 & -8.6 & 6.31 & -8.2 & 6.02 \\
\hline 5 & -8.8 & 6.46 & -7.9 & 5.80 & 15 & -8.6 & 6.31 & -6.4 & 4.70 \\
\hline 6 & -8.9 & 6.53 & -8.1 & 5.94 & 16 & -8.4 & 6.16 & -7.0 & 5.14 \\
\hline 7 & -8.0 & 5.87 & -6.9 & 5.06 & Chloroquine & -5.7 & 4.18 & -5.2 & 3.82 \\
\hline 8 & -8.5 & 6.24 & -6.4 & 4.70 & Remdesivir & -7.4 & 5.43 & -5.7 & 4.18 \\
\hline 9 & -9.1 & 6.68 & -8.1 & 5.94 & Amantadine & -4.5 & 3.30 & -4.1 & 3.01 \\
\hline 10 & -9.2 & 6.75 & -6.8 & 4.99 & & & & & \\
\hline
\end{tabular}

Table 8. Vina affinity scoring values $(\Delta \mathrm{G})(\mathrm{kcal} / \mathrm{mol})$ and $\mathrm{pKI}$ for tested compounds.

Based on the obtained results, it can be concluded that the tested derivatives show docking scores in the range of -9.3 to -7.8 and -8.3 to -6.4 for Mpro and PLpro, respectively. The obtained $\Delta \mathrm{G}$ are lower compared to the reference compounds ( -7.4 to -4.5 and -5.7 to -4.1 for Mpro and PLpro, respectively). This indicates that in preliminary in silico studies, hybrids 1-16 show a higher affinity for the proteins used than the reference drugs. Comparing the score values of hybrids $\mathbf{1}-\mathbf{1 6}$ with betulin-5,8-quinolinedione derivatives [18] showed that the introduction of triazole linker between betulin and 1,4-quinone increased the $\Delta G$ value for Mpro and PL pro proteins.

The main protease Mpro, also known as 3CLpro, is one of the coronavirus nonstructural proteins (Nsp5). Inhibition of Mpro would prevent the virus from replication and as a consequence, Mpro is one of the coronavirus proteins designated as potential targets for drug development. According to the crystallographic data, amino acids His41, Met49, and residues $164-168$ of the long strand play an important role in stabilizing the ligand-Mpro complexes [71].

As seen in Figure 8a, the hybrids are localized in the hydrophobic matrix of the protein, but the arrangement depends on the type of the 1,4-quinone moiety. Comparing the score values for Mpro protein shows that in the series of 5,8-quinolinedione (1-4) and 5,8-isoquinolinedione (5-8), the highest $\Delta \mathrm{G}$ values exhibit derivatives with oxo group at the C-3 position of betulin moiety. In the group of 2-methyl-5,8-quinolinedione, better docking scores are obtained for hybrids 10 and 11. However, in the series of 1,4-naphthoquinone derivatives (13-16), the group at the C-3 position of the betulin moiety does not influence the $\Delta \mathrm{G}$.

Ligands 2, 6, and 14, which have the best score values, contain the same betulin moiety but different 1,4-quinone fragments. In the group of 2-methyl-5,8-quinolinedione hybrids, the lowest $\Delta \mathrm{G}$ has hybrid 11. For detailed analysis of molecular docking, complexes of the Mpro with 2, 6, 10, 11, and 14 ligands have been chosen. Complete models of the possible interaction in 3D and 2D views are presented in Figure 9a,e and Figure S6A-E. The detailed data about the type and length of the binding interactions between these ligands and the protein residues are summarized in Table S5. 


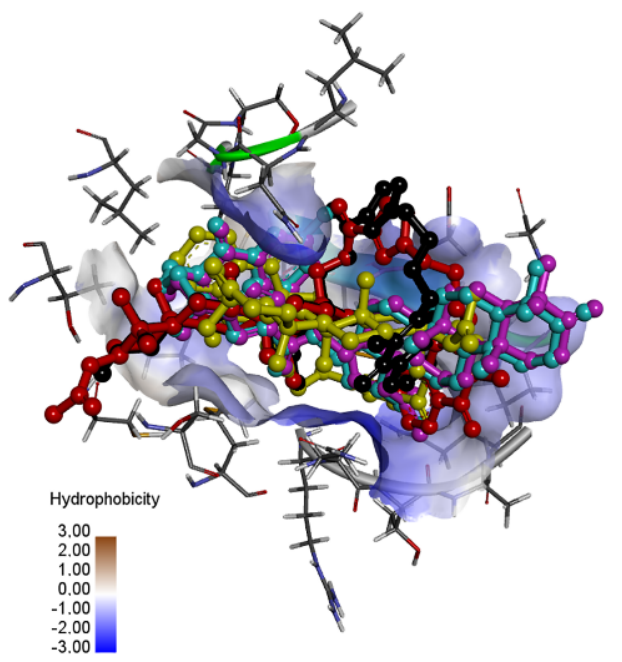

(a)

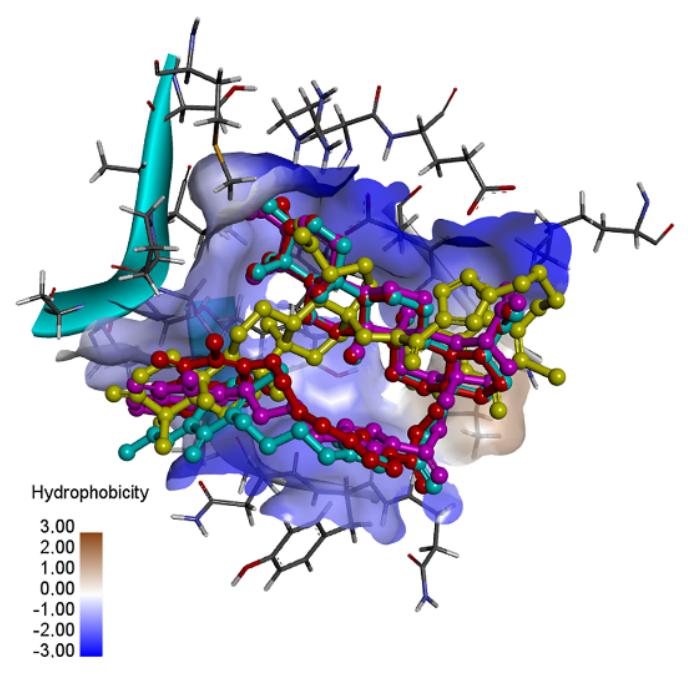

(b)

Figure 8. The superposition of docked ligands: 2 (violet), $\mathbf{6}$ (yellow), 10 (blue), 11 (red), and $\mathbf{1 4}$ (black) in the binding site of (a) Mpro and (b) PLpro.

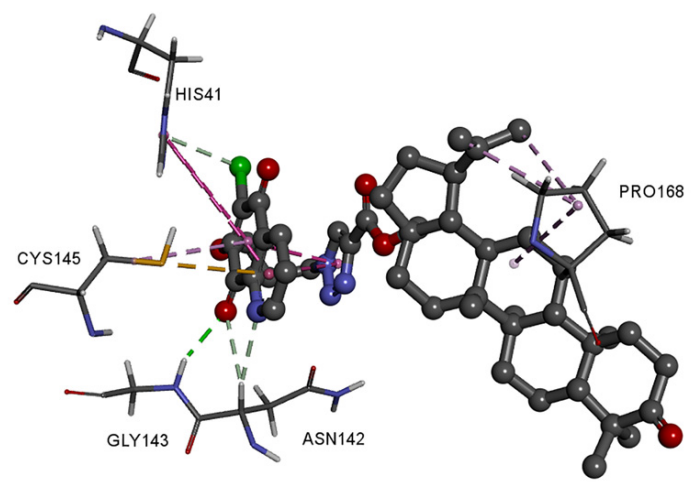

(a)

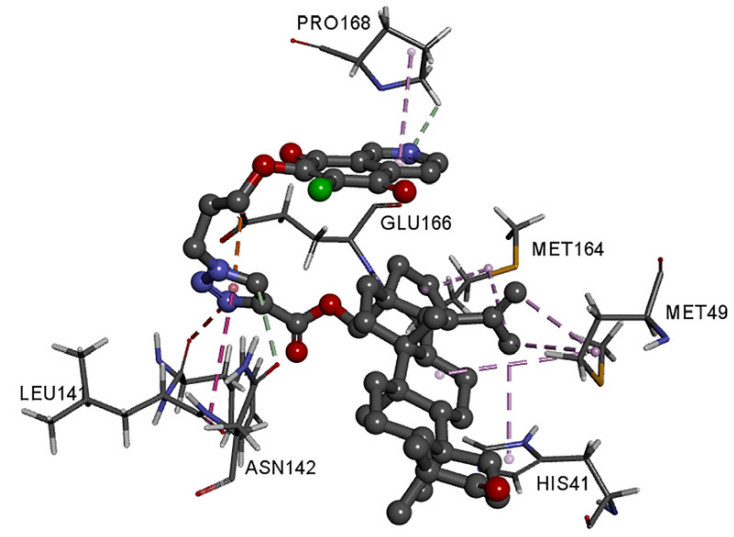

(c)

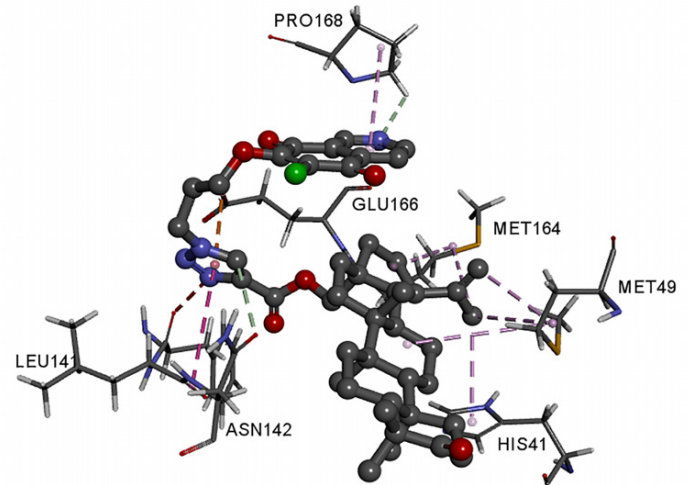

(b)

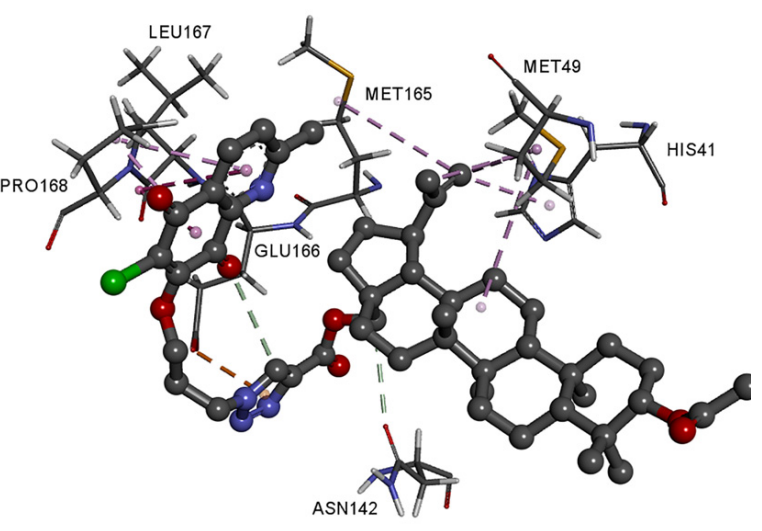

(d)

Figure 9. Cont. 


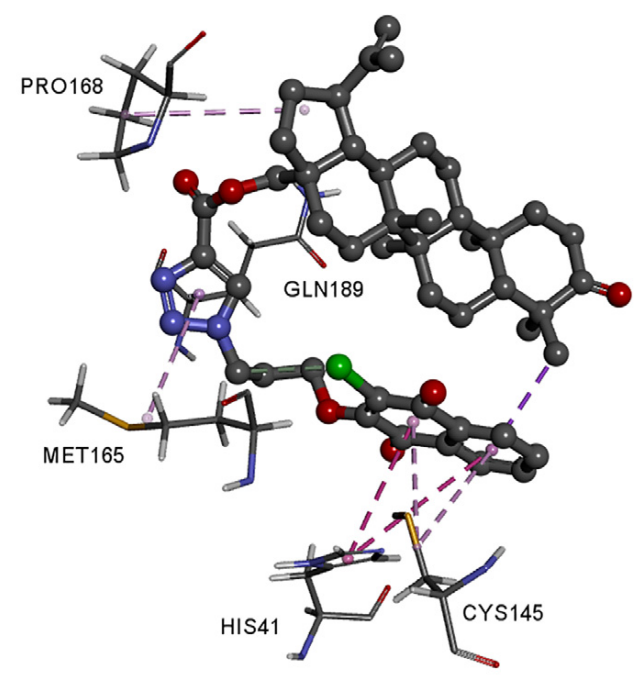

(e)

Figure 9. Docking pose of COVID-19 Mpro protein complex with hybrids (a) 2, (b) 6, (c) 10, (d) 11, and (e) 14.

Comparing the arrangement of hybrids 2, 6, 10 in the active site of the protein shows that the position of nitrogen atoms in the 5,8-quinolinedione moiety influences the interaction between the ligand and the hydrophobic matrix of protein. As seen in Figure 9a,c and Table S5, ligands $\mathbf{2}$ and $\mathbf{1 0}$ create the hydrogen bond and hydrophobic interaction between 1,4-quinone moiety and His41, Asn142, Gly143, and Cys145. In these complexes, the betulin moiety is stabilized by hydrophobic interaction with Pro168. Changing the 5,8-quinolinedione ring to 5,8-isoquinolinedione moiety causes different arrangement of the ligand in the hydrophobic matrix. In complex Mpro-hybrid 6, the nitrogen atom and triazole ring create the hydrogen bond and hydrophobic interaction with Pro168 and Asn142, Glu166, Leu141, respectively (Figure 9b and Figure S7B). In this case, betulin is bound to Met49, Met165, and His41 by hydrophobic interaction. The 1,4-naphthoquione moiety (hybrid 14) interacts with His41, Cys145, Met165, and Gln189 by hydrophobic interaction. Moreover, the triazole unit and betulin moiety are stabilized by hydrophobic interaction with Cys145 and Pro168, respectively (Figure 9e and Figure S6E).

Figure $9 \mathrm{~d}$ and Figure $\mathrm{S} 6 \mathrm{D}$ present the possible interaction of the best fitted compound 11 inside the binding pocket of Mpro. Corresponding amino acids that are significantly involved in the hydrophobic interactions between ligand and the betulin unit are as follows: His41, Met49, and Met165. Moreover, the whole complex is additionally stabilized by the hydrophobic interactions of the newly introduced substituents: the triazole unit with Glu166 and the 1,4-quinone moiety with Leu167 and Pro168.

It should be emphasized that the 1,4-quinone moiety plays an important role in the stabilization of Mpro hybrid complexes.

One of the attractive antiviral drug targets is the SARS-CoV-2 papain-like protease PLpro which is responsible for processing three cleavage sites of the viral polyprotein to release mature nonstructural proteins 1,2, and 3. In the case of PLpro, the drug molecules bind to S3/S4 domains. The S3/S4 pocket contains the residues Asp164, Val165, Arg166, Glu167, Met208, Ala246, Pro247, Pro248, Tyr264, Gly266, Asn267, Tyr268, Gln269, Cys217, Gly271, Tyr273, Thr301, and Asp302 [72].

As seen in Figure 8b, the hybrids are localized in the hydrophobic matrix of the protein, but the type of 1,4-quinone slightly influences the arrangement of the hybrid in the pocket site of proteins. Comparing the score values for PLpro protein shows that in the group of 5,8-quinolinedione hybrids (1-4 and 9-12) the highest values have derivatives with hydroxy group at the C-3 position of betulin moiety, while in the series of 5-8 and 13-16 the best results are obtained for hybrids with the oxo group at this position. 
In each group of 1,4-quinone, we chose one of the best $\Delta \mathrm{G}$, and performed detailed analysis for it. Complete models of the possible interaction in 3D and 2D views are presented in Figure 10a-d and Figure S7A-D. The detailed data about the type and length of the binding interactions between these ligands and the protein residues are summarized in Table S5.

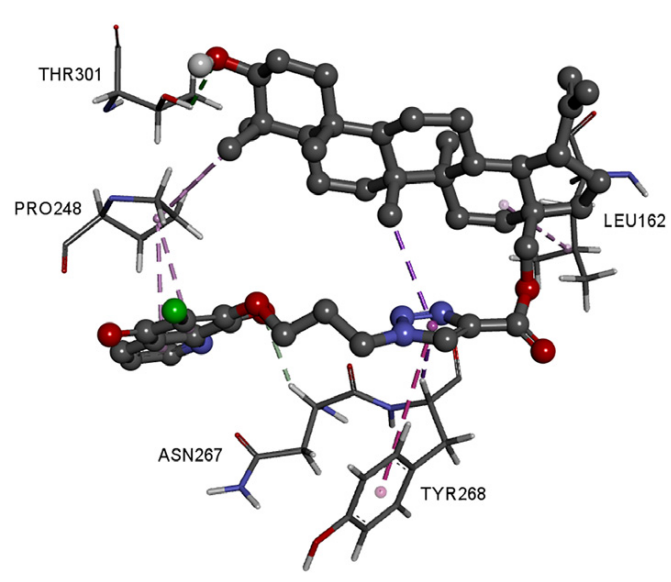

(a)

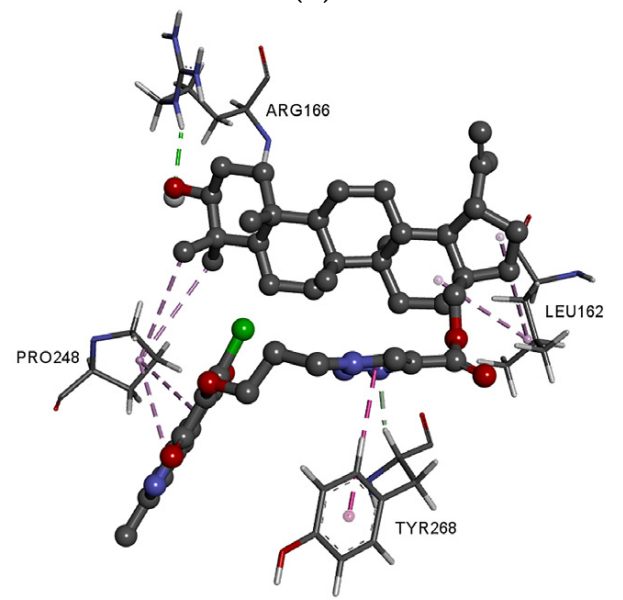

(c)

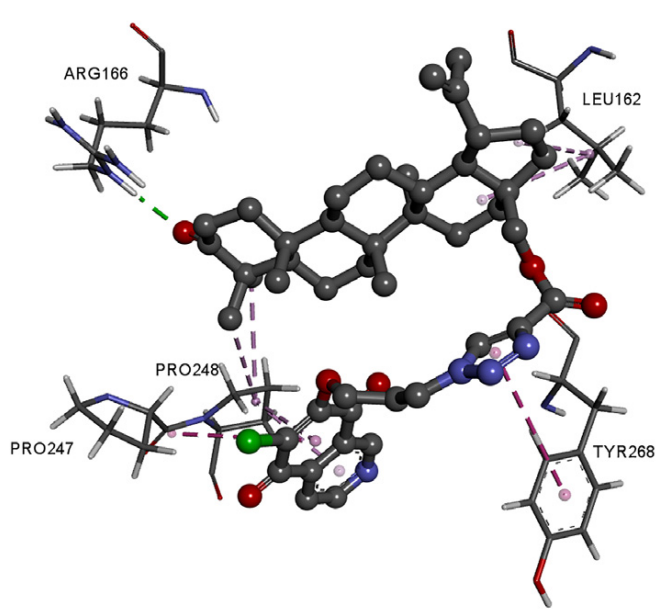

(b)

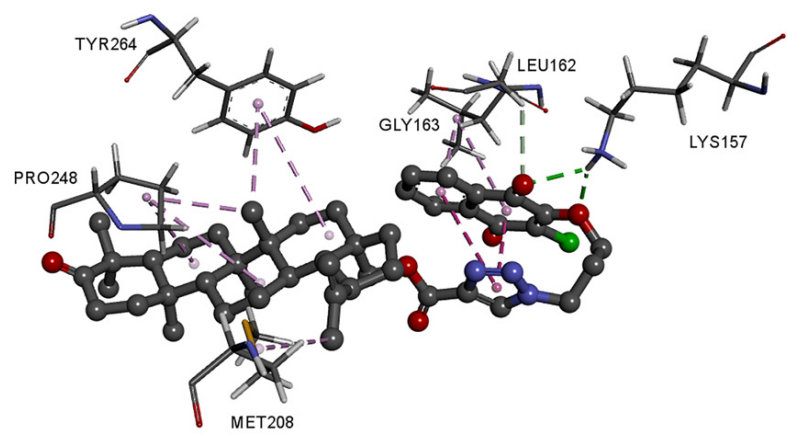

(d)

Figure 10. Docking pose of COVID-19 PLpro protein complex with hybrids (a) 1, (b) 6, (c) 9, and (d) 14.

Comparing the optimal docking post of compounds 1, 6, and 9 shows a general trend that the betulin moiety is bound to Pro248 and Lue162 by hydrophobic interaction (Figure 10a-c and Figure S7A-C). The hydroxyl or carbonyl group at the C-3 position creates a hydrogen bond with Thr301 (1) or Arg166 (6 and 9). The 1,4-quinone moiety and triazole ring are involved in hydrophobic interaction with Pro248 and Tyr268, respectively.

Hybrid with 1,4-naphtoquinone $\mathbf{1 4}$ has a different arrangement in the active site of PLpro than these with 5,8-quinolinedione or 5,8-isoquinolinedione ligands (Figure 10d and Figure S7D). The 1,4-quinone moiety creates two hydrogen bonds with Lys157 and one with Gly163. The complex is stabilized by hydrophobic interaction with Leu162, Pro248, Met208, and Tyr264. In this case, the triazole ring does not interact with the hydrophobic matrix of enzyme.

As indicated by literature date, the molecular, physicochemical, and pharmacokinetic properties can be used to determine the biological activity of the compounds [73,74]. The MLR analysis allows to find correlation between score values $(\Delta G)$, experimental lipophilicity and in silico determined parameters. The MLR equation (8) shows the correlation between the score value for Mpro, experimental lipophilicity $\left(\log \mathrm{P}_{\mathrm{TLC}}\right)$, number of rotat- 
able bonds (RB), and the energy of LUMO ( $E_{\text {LUMO }}$ ) orbitals. The $\Delta \mathrm{G}$ for PLpro correlates with molecular mass (M), number of acceptors of hydrogen bond (HA), and energy of HOMO (E $\mathrm{E}_{\mathrm{HOMO}}$ ) orbitals (Equation (9)).

$$
\begin{gathered}
\Delta \mathrm{G}_{\text {Mpro }}=-0.65 \log \mathrm{P}_{\mathrm{TLC}}+1.04 \mathrm{RB}+0.624 \mathrm{E}_{\mathrm{LUMO}}-3.052 \\
\left(\mathrm{r}=0.788, \mathrm{r}^{2}=0.621, \mathrm{SD}=0.281, F=6.559, p=0.007\right) \\
\Delta \mathrm{G}_{\mathrm{PLpro}}=0.280 \mathrm{M}-0.57 \mathrm{HA}+0.38 \mathrm{E}_{\mathrm{HOMO}}-30.306 \\
\left(\mathrm{r}=0.844, \mathrm{r}^{2}=0.712, \mathrm{SD}=0.135, F=9.894, p=0.001\right)
\end{gathered}
$$

The obtained results show that the physicochemical and molecular properties of tested hybrids influence their interaction with the SARS-CoV-2 proteins.

\section{Conclusions}

In the presented study, the lipophilicity of betulin triazole derivatives with attached 1,4quinone moiety was determined and analyzed in terms of structure, physicochemical, and pharmacokinetic parameters. Comparing the lipophilicity of betulin triazole derivatives and hybrids with attached 1,4-quinone, the introduction of 1,4-quinone moiety reduces the lipophilicity. The cluster analysis showed a correlation between the molecular structure of hybrids and their experimental and calculated lipophilicity that can be used to predict these values when designing new compounds. The bioavailability of the tested compound was described by pharmacokinetic and physicochemical properties using the Lipinski and Veber rules. The obtained in silico parameters showed that most of the hybrids could be applied orally and they did not exhibit the neurotoxic activity.

For compounds with attached 1,4-quinone, the LUMO orbitals were mainly delocalized at the 1,4-quinone moiety. Localization of HOMO orbitals depended on the type of substituent at the C-3 position of the betulin moiety. The molecular properties depended on the type of 1,4-quinone moiety. The molecular electrostatic potential showed that the negative potential sites are present in the nucleophilic atoms, i.e., nitrogen and oxygen atoms. The arrangement of the charge depends on the type of 1,4-quinone moiety.

The molecular docking study showed that betulin triazole derivatives with attached 1,4-quinone can inhibit selected SARS-CoV-2 proteins. The high affinity score values of Mpro and PLpro proteins resulted from the introduction of the triazole ring as a linker connecting the betulin moiety with the 1,4-quinone fragment. The multilinear regression equation showed the correlation between the score values for Mpro and PLpro proteins, and experimental lipophilicity $\left(\log \mathrm{P}_{\mathrm{TLC}}\right)$, molecular descriptors, and global properties. The study showed that the determination of these parameters allows for the prediction of the interactions between the ligand and SARS-CoV-2 proteins.

Supplementary Materials: The following are available online at https: / www.mdpi.com/article / $10.3390 /$ pharmaceutics13060781/s1, Table S1. The experimental of lipophilicity $\left(\log \mathrm{P}_{\mathrm{TLC}}\right)$ and hydrophobic index $\left(\varphi_{0}\right)$ for compounds 1-20, Table S2. The calculated lipophilicity for compounds 1-20, Table S3. The experimental and predicted $\log P$, Table S4. The local minima of hybrids 1-16, Table S5. Interaction of hybrids 1, 2, 6, 9, 10, 11, and 14 with active site of Mpro and PL protein, Figure S1. The optimized structure of hybrids 1-16, Figure S2. The linear regression between the experimental and literature lipophilicity for standard substance, Figure S3. The similarity analysis of pharmacokinetic parameters of hybrids 1-16, Figure S4. The HOMO and LUMO orbitals for hybrids 1-16, Figure S5. The MEP for hybrids 1-16, Figure S6. Docking pose of COVID-19 Mpro protein complex with hybrids 2 (A), 6 (B), 10 (C), 11 (D), and 14 (E), Figure S7. Docking pose of COVID-19 PLpro protein complex with hybrids 1 (A), 6 (B), 9 (C), and 14 (D).

Author Contributions: M.K.-T. and S.B. developed the concept of this work; M.J., E.B., and E.C. participated in evaluating the experimental and theoretical lipophilicity; K.M. developed the molecular docking study. M.K.-T. wrote the manuscript. All authors have read and agreed to the published version of the manuscript. 
Funding: This work was supported by the Medical University of Silesia in Katowice, Poland. Grant no. PCN-2-006/K/0/F. Calculations were carried out using resources provided by Wroclaw Centre for 818 Networking and Supercomputing (http:/ / wcss.pl), grant no. 382.

Institutional Review Board Statement: Not applicable.

Informed Consent Statement: Not applicable.

Data Availability Statement: Not applicable.

Conflicts of Interest: The authors declare no conflict of interest.

\section{References}

1. Arnott, J.; Planey, S. The influence of lipophilicity in drug discovery and design. Expert Opin. Drug Discov. 2021, 7, 863-875. [CrossRef]

2. Hammoudi, N.-E.-H.; Sobhi, W.; Attoui, A.; Lemaoui, T.; Erto, A.; Benguerba, Y. In silico drug discovery of Acetylcholinesterase and Butyrylcholinesterase enzymes inhibitors based on Quantitative Structure-Activity Relationship (QSAR) and drug-likeness evaluation. J. Mol. Struct. 2021, 1229, 129845. [CrossRef]

3. Mougin, J.; Bourgaux, C.; Couvreur, P. Elongated self-assembled nanocarriers: From molecular organization to therapeutic applications. Adv. Drug Deliv. Rev. 2021, 172, 127-147. [CrossRef] [PubMed]

4. Duggal, D. Role of nanotechnology in new drug delivery systems. Int. J. Drug Dev. Res. 2011, 4, 4-8.

5. Kovačević, S.; Banjac, M.; Milošević, N.; Ćurčić, J.; Marjanović, D.; Todorović, N.; Krmar, J.; Podunavac-Kuzmanović, S.; Banjac, N.; Ušćumlić, G. Comparative chemometric and quantitative structure-retention relationship analysis of aniso-tropic lipophilicity of 1-arylsuccinimide derivatives determined in high-performance thin-layer chromatography system with aprotic solvents. J. Chromatogr. A 2020, 1628, 461439. [CrossRef] [PubMed]

6. Tshepelevitsh, S.; Kadam, S.A.; Darnell, A.; Bobacka, J.; Rüütel, A.; Haljasorg, T.; Leito, I. LogP determination for highly lipophilic hydrogen-bonding anion receptor molecules. Anal. Chim. Acta 2020, 1132, 123-133. [CrossRef] [PubMed]

7. Kulig, K.; Malawska, B. RP-TLC determination of the lipophilicity of 1-substituted pyrrolidin-2-one derivatives. Correlation of lipophilicity with affinity for $\alpha$-adrenoceptors. JPC J. Planar Chromatogr. Mod. TLC 2009, 22, 141-144. [CrossRef]

8. Bolzán, A.D.; Bianchi, M.S. Genotoxicity of streptonigrin: A review. Mutat. Res. Rev. Mutat. Res. 2001, 488, 25-37. [CrossRef]

9. Boger, D.L.; Yasuda, M.; Mitscher, L.A.; Drake, S.D.; Kitos, P.A.; Thompson, S.C. Streptonigrin and lavendamycin partial structures. Probes for the minimum, potent pharmacophore of streptonigrin, lavendamycin, and synthetic quinoline-5,8-diones. J. Med. Chem. 1987, 30, 1918-1928. [CrossRef]

10. Kadela-Tomanek, M.; Bębenek, E.; Chrobak, E.; Boryczka, S. 5,8-Quinolinedione Scaffold as a Promising Moiety of Bioactive Agents. Molecules 2019, 24, 4115. [CrossRef] [PubMed]

11. Kadela-Tomanek, M.; Jastrzębska, M.; Chrobak, E.; Bębenek, E.; Latocha, M.; Kusz, J.; Boryczka, S. Structural and spectral characterisation of 2-amino-2H-[1,2,3]triazolo[4,5-g]quinoline-4,9-dione polymorphs. Cytotoxic activity and molecu-lardocking study with NQO1 enzyme. Spectrochim. Acta A Mol. Biomol. Spectrosc. 2020, 230, 118038-118050. [CrossRef] [PubMed]

12. Kadela-Tomanek, M.; Bębenek, E.; Chrobak, E.; Latocha, M.; Boryczka, S. Alkoxy and enediyne eerivatives containing 1,4benzoquinone subunits-synthesis and antitumor activity. Molecules 2017, 22, 447. [CrossRef] [PubMed]

13. Kadela-Tomanek, M.; Jastrzębska, M.; Bębenek, E.; Chrobak, E.; Latocha, M.; Kusz, J.; Tarnawska, D.; Boryczka, S. New Acetylenic Amine Derivatives of 5,8-Quinolinediones: Synthesis, Crystal Structure and Antiproliferative Activity. Crystals $2017,7,15$. [CrossRef]

14. Kadela-Tomanek, M.; Bębenek, E.; Chrobak, E.; Marciniec, K.; Latocha, M.; Kuśmierz, D.; Jastrzębska, M.; Boryczka, S. Betulin-1,4quinone hybrids: Synthesis, anticancer activity and molecular docking study with NQO1 enzyme. Eur. J. Med. Chem. 2019, 177, 302-315. [CrossRef]

15. Bayrak, N. Novel azanaphtoquinone compounds with aromatic amino moiety: Synthesis, structural characterization, and antimicrobial features. J. Mol. Struct. 2019, 1195, 411-416. [CrossRef]

16. Gholampour, M.; Sakhteman, A.; Pirhadi, S.; Seradj, H. In silico design of novel diamino-quinoline-5,8-dione derivatives as putative inhibitors of $\mathrm{NAD}(\mathrm{P}) \mathrm{H}$ :Quinone oxidoreductase 1 based on docking studies and molecular dynamics simulations. J. Mol. Struct. 2021, 1230, 129906. [CrossRef]

17. Ling, Y.; Yang, Q.-X.; Teng, Y.-N.; Chen, S.; Gao, W.-J.; Guo, J.; Hsu, P.-L.; Liu, Y.; Morris-Natschke, S.L.; Hung, C.-C.; et al. Development of novel amino-quinoline-5,8-dione derivatives as NAD(P)H:quinone oxidoreductase 1 (NQO1) inhibitors with potent antiproliferative activities. Eur. J. Med. Chem. 2018, 154, 199-209. [CrossRef] [PubMed]

18. Kadela-Tomanek, M.; Marciniec, K.; Jastrzębska, M.; Bębenek, E.; Chrobak, E.; Boryczka, S. Spectroscopic investigations, computational analysis and molecular docking to SARS-Co-2 targets studies of 5,8-quinolinedione attached to betulin de-rivatives. Crystals 2021, 11, 76. [CrossRef]

19. Kadela-Tomanek, M.; Pawełczak, B.; Jastrzebska, M.; Bębenek, E.; Chrobak, E.; Latocha, M.; Kusz, J.; Książek, M.; Boryczka, S. Structural, vibrational and quantum chemical investigations for 6,7-dichloro-2-methyl-5,8-quinolinedione. Cytotoxic and molecular docking studies. J. Mol. Struct. 2018, 1168, 73-83. [CrossRef] 
20. Kadela-Tomanek, M.; Bober, K.; Bębenek, E.; Chrobak, E.; Boryczka, S. Application of thin-layer chromatography to evaluate the lipophilicity of 5,8-quinolinedione compounds. J. Planar Chromatogr. Mod. TLC 2017, 30, 219-224. [CrossRef]

21. Kadela-Tomanek, M.; Jastrzębska, M.; Chrobak, E.; Bębenek, E.; Boryczka, S. Chromatographic and Computational Screening of Lipophilicity and Pharmacokinetics of Newly Synthesized Betulin-1,4-quinone Hybrids. Processes 2021, 9, 376. [CrossRef]

22. Ezeokonkwo, M.A.; Ibeanu, F.; Eze, C.; Ibezim, A.; Ezeokoye, C.; Ezenwa, O.; Ezeoka, T.; Vincent, O. Synthesis, antimi-crobial activity and molecular docking studies of 7-bromoquinoline-5,8-dione containing aryl sulphonamides. Int. J. Appl. Chem. 2019, 15, 99-112.

23. Musioł, R.; Jampiledek, J.; Podeszwa, B.; Finster, J.; Tabak, D.; Dohnal, J.; Polański, J. RP-HPLC determination of lipo-philicity in series of quinoline derivatives. Cent. Eur. J. Chem. 2009, 7, 586-597.

24. Atia, A.; Alrawaiq, N.; Abdullah, A. A review of NAD(P)H: Quinone oxidoreductase 1 (NQO1); a multifunctional anti-oxidant enzyme. J. Appl. Pharm. Sci. 2014, 4, 118-122.

25. Valdés, K.; Morales, J.; Rodríguez, L.; Günther, G. Potential use of nanocarriers with pentacyclic triterpenes in cancer treatments. Nanomedicine 2016, 11, 3139-3156. [CrossRef] [PubMed]

26. Mukherjee, B.; Al Hoque, A.; Dutta, D.; Paul, B.; Mukherjee, A.; Mallick, S. Nanoformulated Drug Delivery of Potential Betulinic Acid Derivatives: A Promising Approach Toward Cancer Therapy. In Nanomedicine for Bioactives; Springer: New York, NY, USA, 2020; pp. 127-153.

27. Kazakova, O.B.; Smirnova, I.E.; Baltina, L.A.; Boreko, E.I.; Savinova, O.V.; Pokrovskii, A.G. Antiviral Activity of Acyl Derivatives of Betulin and Betulinic and Dihydroquinopimaric Acids. Russ. J. Bioorgan. Chem. 2018, 44, 740-744. [CrossRef]

28. Zhao, Y.; Chen, C.-H.; Morris-Natschke, S.L.; Lee, K.-H. Design, synthesis, and structure activity relationship analysis of new betulinic acid derivatives as potent HIV inhibitors. Eur. J. Med. Chem. 2021, 215, 113287. [CrossRef] [PubMed]

29. Karagöz, A.Ç.; Leidenberger, M.; Hahn, F.; Hampel, F.; Friedrich, O.; Marschall, M.; Kappes, B.; Tsogoeva, S.B. Synthesis of new betulinic acid/betulin-derived dimers and hybrids with potent antimalarial and antiviral activities. Bioorgan. Med. Chem. 2019, 27, 110-115. [CrossRef] [PubMed]

30. Bębenek, E.; Jastrzębska, M.; Kadela-Tomanek, M.; Chrobak, E.; Orzechowska, B.; Zwolińska, K.; Latocha, M.; Mertas, A.; Czuba, Z.; Boryczka, S. Novel Triazole Hybrids of Betulin: Synthesis and Biological Activity Profile. Molecules 2017, $22,1876$. [CrossRef] [PubMed]

31. Amiri, S.; Dastghaib, S.; Ahmadi, M.; Mehrbod, P.; Khadem, F.; Behrouj, H.; Aghanoori, M.; Machaj, F.; Ghamsari, M.; Rosik, J.; et al. Betulin and its de-rivatives as novel compounds with different pharmacological effects. Biotechnol. Adv. 2020, 38, 107409. [CrossRef]

32. Zhang, D.-H.; Wu, K.-L.; Zhang, X.; Deng, S.-Q.; Peng, B. In silico screening of Chinese herbal medicines with the potential to directly inhibit 2019 novel coronavirus. J. Integr. Med. 2020, 18, 152-158. [CrossRef]

33. Wen, C.-C.; Kuo, Y.-H.; Jan, J.-T.; Liang, P.-H.; Wang, S.-Y.; Liu, H.-G.; Lee, C.-K.; Chang, S.-T.; Kuo, C.-J.; Lee, S.-S.; et al. Specific Plant Terpenoids and Lignoids Possess Potent Antiviral Activities against Severe Acute Respiratory Syndrome Coronavirus. J. Med. Chem. 2007, 50, 4087-4095. [CrossRef] [PubMed]

34. Kadioglu, O.; Saeed, M.; Greten, H.J.; Efferth, T. Identification of novel compounds against three targets of SARS CoV-2 coronavirus by combined virtual screening and supervised machine learning. Comput. Biol. Med. 2021, 133, 104359. [CrossRef] [PubMed]

35. Marciniec, K.; Chrobak, E.; Dabrowska, A.; Bębenek, E.; Kadela-Tomanek, M.; Pęcak, P.; Boryczka, S. Phosphate deriva-tives of 3-carboxyacylbetulin: Synthesis, in vitro anti-HIV and molecular docking study. Biomoleclues 2020, 10, 1148. [CrossRef]

36. Kadela-Tomanek, M.; Jastrzębska, M.; Marciniec, K.; Chrobak, E.; Bębenek, E.; Latocha, M.; Kuśmierz, D.; Boryczka, S. Design, synthesis and biological activity of 1,4-quinone moiety attached to betulin derivatives as potent DT-diaphorase substrate. Bioorganic Chem. 2021, 106, 104478. [CrossRef] [PubMed]

37. Bębenek, E.; Bober-Majnusz, K.; Siudak, S.; Chrobak, E.; Kadela-Tomanek, M.; Wietrzyk, J.; Boryczka, S. Application of TLC to Evaluate the Lipophilicity of Newly Synthesized Betulin Derivatives. J. Chromatogr. Sci. 2020, 58, 323-333. [CrossRef] [PubMed]

38. Virtual Computational Chemistry Laboratory. Available online: http://www.vcclab.org/lab/alogps/ (accessed on 24 April 2021).

39. Molinspiration. Available online: https://www.molinspiration.com/services/logp.html (accessed on 24 April 2021).

40. SwissADME. Available online: http://www.swissadme.ch/index.php (accessed on 24 April 2021).

41. Daina, A.; Michielin, O.; Zoete, V. SwissADME: A free web tool to evaluate pharmacokinetics, drug-likeness and medicinal chemistry friendliness of small molecules. Sci. Rep. 2017, 7, 42717. [CrossRef] [PubMed]

42. pkCSM. Available online: http://biosig.unimelb.edu.au/pkcsm/prediction\# (accessed on 24 April 2021).

43. Pires, D.E.V.; Blundell, T.L.; Ascher, D.B. pkCSM: Predicting Small-Molecule Pharmacokinetic and Toxicity Properties Using Graph-Based Signatures. J. Med. Chem. 2015, 58, 4066-4072. [CrossRef]

44. Frisch, M.J.; Trucks, G.W.; Schlegel, H.B.; Scuseria, G.E.; Robb, M.A.; Cheeseman, J.R.; Scalmani, G.; Barone, V.; Mennucci, B.; Petersson, G.A.; et al. Gaussian 16, Revision A. 03. Wallingford 2016, 1, 3.

45. Politzer, P.; Laurence, P.; Jayasuriya, K. Molecular electrostatic potentials: An effective tool for the elucidation of bio-chemical phenomena. Environ. Health Perspect. 1985, 61, 191-202. [CrossRef] [PubMed]

46. Dennington, R.; Keith, T.; Millam, J. GaussView Version 5; Semichem Inc.: Shawnee Mission, KS, USA, 2009.

47. PerkinElmer ChemOffice Suite. Available online: https / / www.perkinelmer.com (accessed on 24 April 2021). 
48. Morris, G.M.; Huey, R.; Lindstrom, W.; Sanner, M.F.; Belew, R.K.; Goodsell, D.S.; Olson, A.J. AutoDock4 and AutoDockTools4: Automated docking with selective receptor flexibility. J. Comput. Chem. 2009, 30, 2785-2791. [CrossRef] [PubMed]

49. Trott, O.; Olson, A.J. AutoDock Vina: Improving the speed and accuracy of docking with a new scoring function, efficient optimization, and multithreading. J. Comput. Chem. 2010, 31, 455-461. [CrossRef] [PubMed]

50. Dallakyan, S.; Olson, A.J. Small-molecule library screening by docking with PyRx. Methods Mol. Biol. 2015, 1263, 243-250. [PubMed]

51. Dessault Systemes BIOVIA. Available online: https://www.3dsbiovia.com/products/collaborative-science/biovia-discoverystudio/ (accessed on 24 April 2021).

52. Mannhold, R.; Cruciani, G.; Dross, K.; Rekker, R. Multivariate analysis of experimental and computational descriptors of molecular lipophilicity. J. Comput. Mol. Des. 1998, 12, 573-581. [CrossRef] [PubMed]

53. Bodor, N.; Gabanyi, Z.; Wong, C.K. A new method for the estimation of partition coefficient. J. Am. Chem. Soc. 1989, 11, 3783-3786. [CrossRef]

54. Lipinski, C.A.; Lombardo, F.; Dominy, B.W.; Feeney, P.J. Experimental and computational approaches to estimate solubility and permeability in drug discovery and development settings. Adv. Drug Deliv. Rev. 2001, 46, 3-26. [CrossRef]

55. Veber, D.F.; Johnson, S.R.; Cheng, H.-Y.; Smith, B.R.; Ward, K.W.; Kopple, K.D. Molecular Properties That Influence the Oral Bioavailability of Drug Candidates. J. Med. Chem. 2002, 45, 2615-2623. [CrossRef] [PubMed]

56. Šegan, S.; Penjišević, J.; Šukalović, V.; Andrić, D.; Milojković-Opsenica, D.; Kostić-Rajačić, S. Investigation of lipophilicity and pharmacokinetic properties of 2-(methoxy)phenylpiperazine dopamine D2 ligands. J. Chromatogr. B 2019, 1124, 146-153. [CrossRef] [PubMed]

57. Johnson, T.W.; Dress, K.R.; Edwards, M. Using the Golden Triangle to optimize clearance and oral absorption. Bioorganic Med. Chem. Lett. 2009, 19, 5560-5564. [CrossRef]

58. Kulkarni, A.; Han, Y.; Hopfinger, A. Predicting Caco-2 cell permeation coefficients of organic molecules using mem-braneinteraction QSAR analysis. J. Chem. Inf. Comput. Sci. 2002, 42, 331-342. [CrossRef]

59. Feher, M.; Schmidt, J.M. Property Distributions: Differences between Drugs, Natural Products, and Molecules from Combinatorial Chemistry. J. Chem. Inf. Comput. Sci. 2002, 43, 218-227. [CrossRef] [PubMed]

60. Hutter, M.C. Prediction of blood-brain barrier permeation using quantum chemically derived information. J. Comput. Mol. Des. 2003, 17, 415-443. [CrossRef] [PubMed]

61. Govindarajan, M.; Karabacak, M.; Periandy, S.; Tanuja, D. Spectroscopic (FT-IR, FT-Raman, UV and NMR) investigation and NLO, HOMO-LUMO, NBO analysis of organic 2,4,5-trichloroaniline. Spectrochim. Acta Part A Mol. Biomol. Spectrosc. 2012, 97, 231-245. [CrossRef] [PubMed]

62. Kumar, S.; Saini, V.; Maurya, I.K.; Sindhu, J.; Kumari, M.; Kataria, R.; Kumar, V. Design, synthesis, DFT, docking studies and ADME prediction of some new coumarinyl linked pyrazolylthiazoles: Potential standalone or adjuvant antimicrobial agents. PLoS ONE 2018, 13, e0196016. [CrossRef] [PubMed]

63. Singha, P.; Islama, S.; Ahmada, H.; Prabaharan, A. Spectroscopic investigation (FT-IR, FT-Raman), HOMO-LUMO, NBO, and molecular docking analysis of N-ethyl-N-nitrosourea, a potential anticancer agent. J. Mol. Struct. 2018, 1154, 39-50. [CrossRef]

64. Zhou, Z.; Liu, Y.; Ren, Q.; Yu, D.; Lu, H. Synthesis, crystal structure and DFT study of a novel compound N-(4-(2,4dimorpholinopyrido[2,3-d]pyrimidin-6-yl)phenyl)pyrrolidine-1-carboxamide. J. Mol. Struct. 2021, 1235, 130261. [CrossRef]

65. Mary, Y.S.; Mary, Y.S.; Krátký, M.; Vinsova, J.; Baraldi, C.; Gamberin, M.C. DFT, molecular docking and SERS (concen-tration and solvent dependant) investigations of a methylisoxazole derivative with potential antimicrobial activity. J. Mol. Struct. 2021, 1232, 130034. [CrossRef]

66. Chandrasekaran, K.; Kumar, R.T. Structural, spectral, thermodynamical, NLO, HOMO, LUMO and NBO analysis of fluconazole. Spectrochim. Acta Part A Mol. Biomol. Spectrosc. 2015, 150, 974-991. [CrossRef]

67. World Health Organization. WHO Coronavirus Disease (COVID-19) Dashboard. 2020. Available online: https:/ / covid19.who.int/ (accessed on 3 March 2021).

68. Oscanoa, T.; Romero-Ortuno, R.; Carvajal, A.; Savarino, A. A pharmacological perspective of chloroquine in SARS-CoV-2 infection: An old drug for the fight against a new coronavirus? Int. J. Antimicrob. Agents 2020, 56, 106078. [CrossRef]

69. Ko, W.; Rolain, J.; Lee, N.; Chen, P.; Huang, C.; Lee, P.; Hsueh, P. Arguments in favour of remdesivir for treating SARS-CoV-2 infections. Int. J. Antimicrob. Agents 2020, 55, 105933. [CrossRef]

70. Borra, A. Does amantadine have a protective effect against COVID-19? Neurol. Neurochir. Pol. 2020, 54, 284-285. [CrossRef] [PubMed]

71. Jin, Z.; Du, X.; Xu, Y.; Deng, Y.; Liu, M.; Zhao, Y.; Zhang, B.; Li, X.; Zhang, L.; Peng, C.; et al. Structure of Mpro from SARS-CoV-2 and discovery of its inhibitors. Nature 2020, 582, 289-293. [CrossRef] [PubMed]

72. Arya, R.; Das, A.; Prashar, V.; Kumar, M. Potential inhibitors against papain-like protease of novel coronavirus (SARS-CoV-2) from FDA approved drugs. ChemRxiv 2020, 1-10. [CrossRef]

73. Oashi, T.; Ringer, A.L.; Raman, E.P.; MacKerell, A.D. Automated Selection of Compounds with Physicochemical Properties to Maximize Bioavailability and Druglikeness. J. Chem. Inf. Model. 2010, 51, 148-158. [CrossRef] [PubMed]

74. Lagorce, D.; Douguet, D.; Miteva, M.A.; Villoutreix, B.O. Computational analysis of calculated physicochemical and ADMET properties of protein-protein interaction inhibitors. Sci. Rep. 2017, 7, srep46277. [CrossRef] [PubMed] 